\title{
Deficiency of CPEB2-Confined Choline Acetyltransferase Expression in the Dorsal Motor Nucleus of Vagus Causes Hyperactivated Parasympathetic Signaling-Associated Bronchoconstriction
}

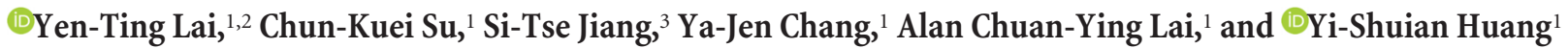 \\ ${ }^{1}$ Institute of Biomedical Sciences, Academia Sinica, 11529 Taipei, Taiwan, ${ }^{2}$ Graduate Institute of Microbiology, College of Medicine, National Taiwan \\ University, 10051 Taipei, Taiwan, and ${ }^{3}$ National Laboratory Animal Center, National Applied Research Laboratories, 10622 Tainan, Taiwan
}

Cytoplasmic polyadenylation element binding protein 2 (CPEB2) is an RNA-binding protein and translational regulator. To understand the physiological function of CPEB2, we generated CPEB2 knock-out (KO) mice and found that most died within $3 \mathrm{~d}$ after birth. CPEB2 is highly expressed in the brainstem, which controls vital functions, such as breathing. Whole-body plethysmography revealed that KO neonates had aberrant respiration with frequent apnea. Nevertheless, the morphology and function of the respiratory rhythm generator and diaphragm neuromuscular junctions appeared normal. We found that upregulated translation of choline acetyltransferase in the CPEB2 KO dorsal motor nucleus of vagus resulted in hyperactivation of parasympathetic signaling-induced bronchoconstriction, as evidenced by increased pulmonary acetylcholine and phosphorylated myosin light chain 2 in bronchial smooth muscles. Specific deletion of CPEB2 in cholinergic neurons sufficiently caused increased apnea in neonatal pups and airway hyper-reactivity in adult mice. Moreover, inhalation of an anticholinergic bronchodilator reduced apnea episodes in global and cholinergic CPEB2-KO mice. Together, the elevated airway constriction induced by cholinergic transmission in KO neonates may account for the respiratory defect and mortality.

Key words: bronchoconstriction; ChAT; CPEB; DMNV; SIDS; translational control

\section{Significance Statement}

This study first generated and characterized cpeb2 gene-deficient mice. CPEB2-knock-out (KO) mice are born alive but most die within $3 \mathrm{~d}$ after birth showing no overt defects in anatomy. We found that the KO neonates showed severe apnea and altered respiratory pattern. Such respiratory defects could be recapitulated in mice with pan-neuron-specific or cholinergic neuronspecific ablation of the cpeb2 gene. Further investigation revealed that cholinergic transmission in the KO dorsal motor nucleus of vagus was overactivated because $\mathrm{KO}$ mice lack CPEB2-suppressed translation of the rate-limiting enzyme in the production of acetylcholine (i.e., choline acetyltransferase). Consequently, increased parasympathetic signaling leads to hyperactivated bronchoconstriction and abnormal respiration in the KO neonates.

\section{Introduction}

Cytoplasmic polyadenylation element binding protein 2 (CPEB2) is a sequence-specific RNA-binding protein expressed

Received Feb. 18, 2016; revised Sept. 19, 2016; accepted 0ct. 27, 2016.

Author contributions: Y.-T.L., C.-K.S., S.-T.J., Y.-J.C., and Y.-S.H. designed research; Y.-T.L., A.C.-Y.L., and Y.-S.H. performed research; C.-K.S. contributed unpublished reagents/analytic tools; Y.-T.L. analyzed data; Y.-T.L. and Y.-S.H. wrote the paper.

This work was supported by the Ministry of Science and Technology (102-2628-B-001-007-MY3 and 104-2321B-001-064 to Y.-S.H. and 102-2320-B-001-029-MY3 to Y.-J.C.) in Taiwan. We thank Ching-Feng Cheng for technical support of echocardiography and Cheng-Ting Chien for assistance on neuromuscular junction electrorecording. We appreciate the assistance of Pang-Hsien Tu for helpful suggestions.

The authors declare no competing financial interests.

Correspondence should be addressed to Yi-Shuian Huang, Institute of Biomedical Sciences, Academia Sinica, 128 Section 2, Academia Road, Taipei 11529, Taiwan. E-mail: yishuian@ibms.sinica.edu.tw. abundantly in the brain (Chen and Huang, 2012). Previously, we showed that CPEB2 binds to the eukaryotic translation elongation factor 2 (eEF2) to downregulate eEF2's GTPase activity and repress target RNA translation (Chen and Huang, 2012). To understand the in vivo function of CPEB2, we generated CPEB2knock-out (KO) mice. Unlike with KOs of its closely related family members, CPEB3 and CPEB4 (Chao et al., 2013; Tsai et al., 2013), CPEB2 KO resulted in death in most mice within $3 \mathrm{~d}$ after birth. The early death of $\mathrm{KO}$ mice motivated us to examine whether CPEB2 controls vital functions, such as respiration. 
Proper development of the respiratory network is essential for mammals to acquire oxygen by themselves after birth and survive in the extrauterine environment (Fortin and Thoby-Brisson, 2009). The respiratory rhythm generator (RRG) located in the medulla oblongata is composed of two interacting respiratory oscillators, the pre-Bötzinger complex (pre-BötC) and the parafacial respiratory group (pFRG; Smith et al., 1991; Onimaru et al., 2009). The pre-BötC drives inspiration by activating the premotor neurons of the rostral ventral respiratory group, which in turn project to lower motor neurons in the spinal cord that innervate inspiratory muscles, such as the intercostal muscles and the diaphragm. In contrast, the rhythm of the pFRG is phase-locked with the oscillation of pre-BötC and discharges in the abdominal motor output during active expiration (Feldman et al., 2013). The pFRG is partly overlapped with the retrotrapezoid nucleus, a group of glutamatergic neurons located ventral to the facial motor nucleus (FMN), and confers central chemosensitivity upon the change of blood $\mathrm{CO}_{2} / \mathrm{H}^{+}$concentration (Guyenet and Mulkey, 2010). Several gene-modified mice with developmentally malformed pre-BötC or pFRG die of respiratory failure after birth (Blanchi et al., 2003; Dubreuil et al., 2008; Onimaru et al., 2009; Burgold et al., 2012). Although pre-BötC and pFRG are critical pacemakers to control respiration, both regions can be modulated by inputs from other neuronal networks, such as the (nor)adrenergic system in the pons (A5 and A6) and medulla (A1/C1 and A2/C2; Hilaire, 2006). Several reported KO mice with loss of (nor)adrenergic neurons showed respiratory arrhythmia (Hirsch et al., 1998; Dauger et al., 2001; Qian et al., 2001). In addition, several cranial motor nuclei in the medulla, of which cholinergic signaling is vital to maintain an unimpeded airway for smooth breathing (Bianchi et al., 1995). Among them, the dorsal motor nucleus of vagus (DMNV) and the nucleus ambiguus (NA) are composed of parasympathetic preganglionic neurons whose axons project and innervate many visceral organs, including the heart, trachea, and lung (Bennett et al., 1981; Corbett et al., 1999; Fontán et al., 2000; Jordan, 2001; Takanaga et al., 2003). Activation of these parasympathetic pathways evokes bradycardia, tracheal contraction, and bronchoconstriction (Haselton et al., 1992; Zhang et al., 2006; McGovern and Mazzone, 2010; Llewellyn-Smith and Verberne, 2011). The importance of the NA in neonatal breathing has been implicated in Teashirt 3-null mice, which show severe apoptosis specifically in the NA and probably die of upper-airway collapse coupled with impaired rhythmogenesis in the embryonic pFRG oscillator (Caubit et al., 2010). The significance of the DMNV in neonatal respiration has been implied only in mice deficient in nuclear receptor-related 1 protein (Nurr1). Nurr1-KO neonates with elongated DMNV show hypoventilation-related lethality (Nsegbe et al., 2004), yet no direct evidence established the causal relation between abnormal DMNV and hypoventilation. Given the fact that the DMNV and NA command parasympathetic signaling to regulate cardiorespiratory fitness, both nuclei examined by immunohistochemical and morphological analyses in infants who died from sudden infant death syndrome (SIDS) often show abnormalities (Neff et al., 2003; Huang et al., 2005; Machaalani and Waters, 2008, 2014; Bejjani et al., 2013).

Using whole-body plethysmography, we found that CPEB2-KO pups showed aberrant respiration, with increased apnea. Further characterizations found that CPEB2 confines parasympathetic signaling by downregulating choline acetyltransferase (ChAT) RNA translation in the DMNV to control unimpeded air flow into the lung, which is critical for maintaining normal neonatal respiration.

\section{Materials and Methods}

Construction of the targeting vector for generation of KO mice. The genomic bacterial artificial chromosome (BAC) clone (RP23-432N11) containing the C57BL/6J mouse cpeb2 gene was used to construct the targeting vector by the recombineering technique according to the manufacturer's instructions (Gene Bridges). The cpeb2 gene consists of 13 exons (numbered boxes) and spans a region of $\sim 53 \mathrm{~kb}$. Briefly, a loxP-Neo-loxP cassette was first recombined into the $3^{\prime}$-end of exon 5 and excised with recombinant Cre (New England Biolabs) in vitro to result in a single loxP site. The resulting BAC clone was recombined with the Frt-PGK-NeoFrt-loxP cassette to the $5^{\prime}$-end of exon 3 . The BAC plasmid was linearized with NruI and electroporated into C57BL/6 ES cells. Two correct clones identified in 284 G418-resistant clones were injected into C57BL/6Tyrc-2J (c2J) blastocysts. Only one clone derived a germline-transmitted line. The mouse carrying floxed allele was first crossed with Frt recombinase driven by the $\beta$-actin promoter (RRID:IMSR_JAX:003800) to remove the Frt-PGK-Neo-Frt cassette. The resulting line was maintained as fCPEB2 mice, then crossed with the protamine-Cre (RRID:IMSR_JAX: 003328), nestin-Cre (RRID:IMSR_JAX:003771), or chat-Cre (RRID: IMSR_JAX:018957) transgenic mouse to derive global or conditional KO (cKO) mice.

Animals and genotyping. All of the experimental protocols were performed in accordance with the guidelines of the Institutional Animal Care and Use Committee of Academia Sinica (protocol number 12-03338) and compliant with Taiwan Ministry of Science and Technology guidelines for ethical treatment of animals. All efforts were made to minimize the number of animals used and their suffering. Adult mice were killed by using carbon dioxide euthanasia. Neonatal mice were anesthetized by hypothermia before being killed for experiments. The wild-type (WT) and KO neonates were littermates from heterozygous crosses. The neuron-specific and cholinergic neuron-specific conditional WT (cWT) and cKO mice were obtained from the mating of $c p e b 2^{\mathrm{f} / \mathrm{f},+/+}$ with $c$ peb $2^{\mathrm{f} / \mathrm{f} \text {,nestin-cre/+}}$ and $c p e b 2^{\text {f/f, chat-cre/+}}$ mice. Neonatal and adult mice of both genders were used for this study. The genotypes were determined by PCR of tail biopsies and the KAPA mouse genotyping kit (KAPA Biosystems). Briefly, tail samples were lysed in $20 \mu$ l of KAPA extract buffer for $20 \mathrm{~min}$ at $75^{\circ} \mathrm{C}$, then $5 \mathrm{~min}$ at $95-100^{\circ} \mathrm{C}$. The DNA sample was then diluted with $60 \mu \mathrm{l}$ of $\mathrm{H}_{2} \mathrm{O}$, and $0.5 \mu \mathrm{l}$ was used for a $10 \mu \mathrm{l}$ PCR. The sense primer, CP2F1 5' -CAAATACTAGCAATTCCCAGGTCC-3' and two antisense primers CP2R1 5' - TCTGATGCTACCCATAGGTGGATC- $3^{\prime}$ and CP2R2 5' -TCTGAGCCAAGGAGGAGTTCT-3' at a 2:1:1 ratio were used to amplify the WT and KO alleles of the cpeb2 gene, respectively. The floxed cpeb2 allele was detected with $\mathrm{CP} 2 \mathrm{~F} 1$ and $\mathrm{CP} 2 \mathrm{R} 1$ primers. The presence of the cre transgene was PCR-monitored with CreF 5'-TTACCGGTCGATG CAACGAGTGATG-3' and CreR 5'-GTGAAACAGCATTGCTGTC ACTT-3' primers.

Antibodies and chemicals. Antibodies used were ChAT (Millipore, catalog \#AB144P; RRID:AB_2079751), neurofilament heavy chain (NF-H; Millipore, catalog \#AB5539; RRID:AB_177520), tyrosine hydroxylase (TH; Millipore, catalog \#AB152; RRID:AB_390204), $\alpha$-smooth muscle actin ( $\alpha$ SMA; Abcam, catalog \#ab7817; RRID:AB_262054), neurokinin 1 receptor 1 (NK1R; Sigma-Aldrich, catalog \#S8305; RRID:AB_261562), $\beta$-actin (Sigma-Aldrich, catalog \#A5441; RRID:AB_476744), $\alpha$-tubulin (SigmaAldrich, catalog \#T5168; RRID:AB_477579), p-Mlc2/Ser19 (Cell Signaling Technology, catalog \#3671S; RRID:AB_330248), and $\beta 3$-tubulin (Cell Signaling Technology, catalog \#5666P; RRID:AB_10691594). CPEB2, CPEB3, and CPEB4 antibodies have been described previously (Chen and Huang, 2012; Chao et al., 2013; Chang and Huang, 2014). Fluorescein isothiocyanate (FITC)-conjugated donkey anti-chicken IgY was from Jackson ImmunoResearch (catalog \#703-095-155; RRID:AB_2340356). Alexa Fluor-conjugated $\alpha$-bungarotoxin and secondary antibodies were from Invitrogen. Tiotropium bromide (sc220259) was from Santa Cruz Biotechnology. Methacholine (A2251) and Avertin (T48402) were from Sigma-Aldrich.

Immunohistochemistry, image acquisition, and quantification. The brainstems isolated from decapitated neonatal mice were fixed in $4 \%$ formaldehyde in PBS overnight at $4^{\circ} \mathrm{C}$, immersed sequentially in PBS containing 20 and $30 \%$ sucrose $(\mathrm{w} / \mathrm{v})$ for $24 \mathrm{~h}$, then mounted in optimal cutting temperature medium for cryosectioning. Unless otherwise spec- 
ified, all procedures were performed at room temperature with solutions prepared in PBS. The coronal sections (16-18 $\mu \mathrm{m}$ thick) of medulla were permeabolized with $0.2 \%$ Triton X-100 for $15 \mathrm{~min}$, blocked in $10 \%$ horse serum and 3\% BSA for $1 \mathrm{~h}$, then incubated with the designated primary antibodies overnight at $4^{\circ} \mathrm{C}$. After three washes with PBS, tissues were incubated with the corresponding Alexa Fluor-conjugated secondary antibodies for $1 \mathrm{~h}$. For preparing postganglionic neuron samples, neonatal mice after hypothermia-induced unconsciousness were transcardially perfused with $4 \%$ formaldehyde and then postfixed in the same solution overnight before paraffin embedding and horizontal sectioning $(5 \mu \mathrm{m}$ thick). The postganglionic samples after dewaxing and rehydration procedures were boiled for $5 \mathrm{~min}$ in $10 \mathrm{~mm}$ sodium citrate buffer, $\mathrm{pH}$, to retrieve antigen, followed by immunofluorescence staining. For whole-mount immunostaining, isolated diaphragms were fixed in $4 \%$ formaldehyde overnight at $4^{\circ} \mathrm{C}$, then permeabolized and blocked in PBS containing $10 \%$ horse serum, $3 \%$ BSA, $0.3 \mathrm{~m}$ glycine, and $0.5 \%$ Triton $\mathrm{X}-100$ overnight at $4^{\circ} \mathrm{C}$. Whole-mount diaphragms were immunostained with NF-H antibody for $3 \mathrm{~d}$ at $4^{\circ} \mathrm{C}$, then washed three times with PBS, followed by overnight incubation of FITC-conjugated secondary antibody and Alexa Fluor 555-conjugated $\alpha$-bungarotoxin at $4^{\circ} \mathrm{C}$. A minimum of three washes with PBS at room temperature were performed between changes of solutions. Fluorescent images were acquired with LSM780 confocal microscopy or Axio Imager Z1 fluorescence microscopy (Carl Zeiss). To compare immunofluorescence signal between WT and KO samples, a pair of postnatal day (P) $1 \mathrm{WT}$ and KO littermate brains were processed at the same time, followed by image acquisition under the same exposure condition to minimize between-batch variation. The mean fluorescence intensities of ChAT in DMNVs, NAs, and FMNs were quantified and adjusted by subtracting the mean background signal in nearby ChAT-negative area using ImageJ $1.47 \mathrm{v}$ (ImageJ, RRID: SCR_003070). The ChAT levels were expressed as a relative ratio with the signal in the WT designated motor nucleus arbitrarily set to 1 . Ratios from 5 to 7 pairwise comparisons between WT and KO as well as cWT and nestin-cKO samples were expressed as mean \pm SEM. The mean fluorescence intensity of ChAT in airway postganglionic neurons was quantified and normalized with that of Tuj1 by ImageJ $1.47 \mathrm{v}$. The data from $5 \mathrm{WT}$ and $7 \mathrm{KO}$ samples were expressed as mean \pm SEM. The mean fluorescence intensity of p-Mlc2 was quantified and normalized with that of $\alpha$ SMA in bronchial smooth muscle by MetaMorph v7.7.5.0 (RRID: SCR_002368). The data from five pairwise comparisons between WT and $\mathrm{KO}$ samples were expressed as mean \pm SEM.

Whole-body plethysmography and echocardiography. All P1 pups were retrieved from their mothers and kept warmed in a humidified oven at $34^{\circ} \mathrm{C}$ for $\geq 20$ min before plethysmographic recording using the Buxco system with some modifications. Calibration was performed once by injecting air of a fixed volume into the animal chamber maintained at $28-30^{\circ} \mathrm{C}$ before experiments. Each breath from the pup inside the animal chamber induced pressure changes between the animal and reference chambers that were detected by the transducer. The barometric signals were transferred to the Buxco MaxII amplifier and filtered through a bandwidth of $0-15 \mathrm{~Hz}$ to eliminate background noises. Each pup was recorded in three $3 \mathrm{~min}$ recording sessions. For monitoring ventilatory responses under hypercapnia, each pup was first recorded under normoxia for two sessions. After a 40 s hypercapnic exposure $\left(8 \% \mathrm{CO}_{2}, 21 \%\right.$ $\mathrm{O}_{2}, 71 \% \mathrm{~N}_{2}$ ), the pup was recorded for an additional $3 \mathrm{~min}$. For the rescue experiment, the minimal effective dose of tiotropium that could block subsequent methacholine-induced respiratory change was first determined in WT mice. Pups in a $350 \mathrm{ml}$ chamber were given 3 min of nebulized tiotropium bromide solution $(\sim 150 \mu \mathrm{l}$ of $25 \mu \mathrm{g} / \mathrm{ml})$ using a nebulizer (AG-AL1000, Aerogen), followed by plethysmographic recording within $24 \mathrm{~h}$. Because breathing movements were recorded noninvasively in unanesthetized pups, only the signals recorded at a resting state were analyzed. The sonograms of unanesthetized pups on a heating pad at $37^{\circ} \mathrm{C}$ were monitored by ultrasound biomicroscopy (Vevo 660, VisualSonics) with a $40 \mathrm{MHz}$ transducer and $23 \mathrm{MHz}$ spectral pulsedwave Doppler. Heart rate and rhythm were determined from pulsed Doppler waveforms.

Brainstem-spinal cord preparation and C4 activity recording. P1 or P2 neonates were induced to unconsciousness by hypothermia, decere- brated, and then immersed in the $4^{\circ} \mathrm{C}$ artificial CSF (aCSF; in mM: 128 $\mathrm{NaCl}, 3 \mathrm{KCl}, 1.5 \mathrm{CaCl}_{2}, 1.0 \mathrm{MgSO}_{4}, 24 \mathrm{NaHCO}_{3}, 0.5 \mathrm{NaH}_{2} \mathrm{PO}_{4}, 30$ D-glucose, and 3 ascorbate, $\mathrm{pH}$ 7.4) equilibrated with $95 \% \mathrm{O}_{2}$ and $5 \%$ $\mathrm{CO}_{2}$. Brainstem-spinal cords were harvested and then trimmed immediately rostral to the superior cerebellar artery and revitalized in oxygenated aCSF for $1 \mathrm{~h}$ at $28^{\circ} \mathrm{C}$. The firing activities of $\mathrm{C} 4$ ventral roots were recorded and the signals were amplified, bandpass-filtered at 10-1000 $\mathrm{Hz}$, and processed by using AxoScope v10.2 (Molecular Devices).

Electro-recording of neuromuscular junctions. Diaphragms with ribs and phrenic nerves were dissected from $\mathrm{P} 1$ neonates and placed in oxygenated Ringer's solution (in mM: $126 \mathrm{NaCl}, 5 \mathrm{KCl}, 24 \mathrm{NaHCO}_{3}, 2 \mathrm{CaCl}$, $1 \mathrm{NaH}_{2} \mathrm{PO}_{4}, 11$ D-glucose, $\mathrm{pH} 7.3$ ) at $25^{\circ} \mathrm{C}$ for $1 \mathrm{~h}$. Microelectrodes of $40-60 \mathrm{~m} \Omega$ resistance when filled with $3 \mathrm{M} \mathrm{KCl}$ were pierced into the central neuromuscular junction (NMJ)-enriched region of muscle fibers. The electric signals were acquired by use of an Axoclamp 900A amplifier and Digidata 1440A, then analyzed by using pClamp 10.2 (Molecular Devices; RRID:SCR_011323) to obtain spontaneous miniature end-plate potentials (mEPPs).

Acetylcholine measurement in the lung. Acetylcholine levels were measured by use of the Amplex Red acetylcholine assay kit (Invitrogen). Briefly, $\mathrm{P} 1$ lungs were homogenized in $50 \mathrm{~mm}$ Tris- $\mathrm{HCl}$ buffer, $\mathrm{pH} 8$. Then $100 \mu \mathrm{l}$ of homogenized lysate was mixed with $100 \mu \mathrm{l}$ of $400 \mu \mathrm{M}$ Amplex Red reagent containing $2 \mathrm{U} / \mathrm{ml}$ horseradish peroxidase, $0.2 \mathrm{U} / \mathrm{ml}$ choline oxidase, and $1 \mathrm{U} / \mathrm{ml}$ acetylcholinesterase and incubated at room temperature for $40 \mathrm{~min}$ before measuring absorbance at $585 \mathrm{~nm}$. The protein concentration of lysates was determined by use of the Pierce BCA protein assay kit (Thermo Fisher Scientific). The data are expressed as micromoles of acetylcholine per micrograms of protein.

Analysis of airway hyper-reactivity in adult mice. The 2-month-old cWT and chat-cKO mice were anesthetized with an intraperitoneal injection of Avertin, and then tracheostomized and ventilated with a cannula at a tidal volume of $0.2 \mathrm{ml}$ and a frequency of 150 breaths $/ \mathrm{min}$. Airway resistance in sedated mice upon challenging with increasing doses of methacholine was measured directly by an invasive plethysmography (FinePointe RC, Buxco) according to the established protocol (Albacker et al., 2013).

Plasmid construction. Mouse ChAT 3'-UTR was PCR-amplified from spinal cord cDNA with the primers 5'-CGGAATTCCCAATGTCCTACAGGAGTCA-3' and $5^{\prime}$-CGGGATCCTGACATTACATTTTATTGAAT ACAG-3'. The amplified DNA fragment was cloned to pGL3 plasmid using EcoRI and BamHI cutting sites.

RNA-immunoprecipitation. For the RNA-immunoprecipitation (RIP) experiment, two brainstems isolated from P1 mice were homogenized in $2 \mathrm{ml}$ of lysis buffer [50 mм HEPES, pH 7.4, $150 \mathrm{~mm} \mathrm{NaCl}, 1 \mathrm{~mm}$ EDTA, $0.5 \%$ Triton X-100, $0.5 \mathrm{~mm}$ DTT, $1 \times$ protease inhibitor mixture (Roche), and $40 \mathrm{U} / \mathrm{ml}$ RNase inhibitor], incubated on ice for $30 \mathrm{~min}$, then centrifuged at $12,000 \times g$ for $15 \mathrm{~min}$. The supernatants were equally divided and incubated with $10 \mu \mathrm{l}$ of protein G beads loaded with $10 \mu \mathrm{g}$ of CPEB2 or control IgG for $3 \mathrm{~h}$ at $4^{\circ} \mathrm{C}$. The beads were washed with $700 \mu \mathrm{l}$ of lysis buffer with protease and RNase inhibitors three times. One-fifth volume of beads was used for Western blot analysis. The remaining beads were incubated in elution buffer (100 mM Tris-Cl, $\mathrm{pH}$ 8.0, $10 \mathrm{~mm}$ EDTA, $1 \% \mathrm{SDS}$, and $20 \mu \mathrm{g} / \mathrm{ml}$ proteinase $\mathrm{K}$ ) at $55^{\circ} \mathrm{C}$ for $30 \mathrm{~min}$, followed by phenol/chloroform extraction and isopropanol precipitation in the presence of $5 \mu \mathrm{g}$ of glycogen as a carrier. The isolated RNAs were reverse transcribed with use of oligo-dT (or random) primer and ImPromII Reverse Transcriptase (Promega). Quantitative PCR was conducted by using the Universal Probe Library and Lightcycler 480 system (Roche). Data analysis involved the comparative $\mathrm{Ct}$ (threshold cycle value) method with the nontargeted RNA, GAPDH mRNA, as reference. The PCR primers used for ChAT were as follows: 5'-CTCCAGCTGGCTTACTACAGG-3' and 5' GGATGGATGCACTCTCATAGG-3'; GAPDH, 5'-GCCAAAAGGGTCATCATCTC-3' ${ }^{\prime}$, and 5' -CACACCCATCACAAACATGG-3'.

Luciferase reporter assay. Neuro-2a cells (CLS Cell Lines Service, cata$\log \# 400394 /$ p451_Neuro-2a; RRID:CVCL_0470) were cultured in DMEM supplemented with $10 \%$ fetal bovine serum. The cells were subcultured in a 12-well plate the day before transfection. Cells in each well were transfected with the DNA mixture containing $0.04 \mu \mathrm{g}$ of plasmid expressing firefly luciferase reporter appended with or without mouse ChAT 3'-UTR, 
A

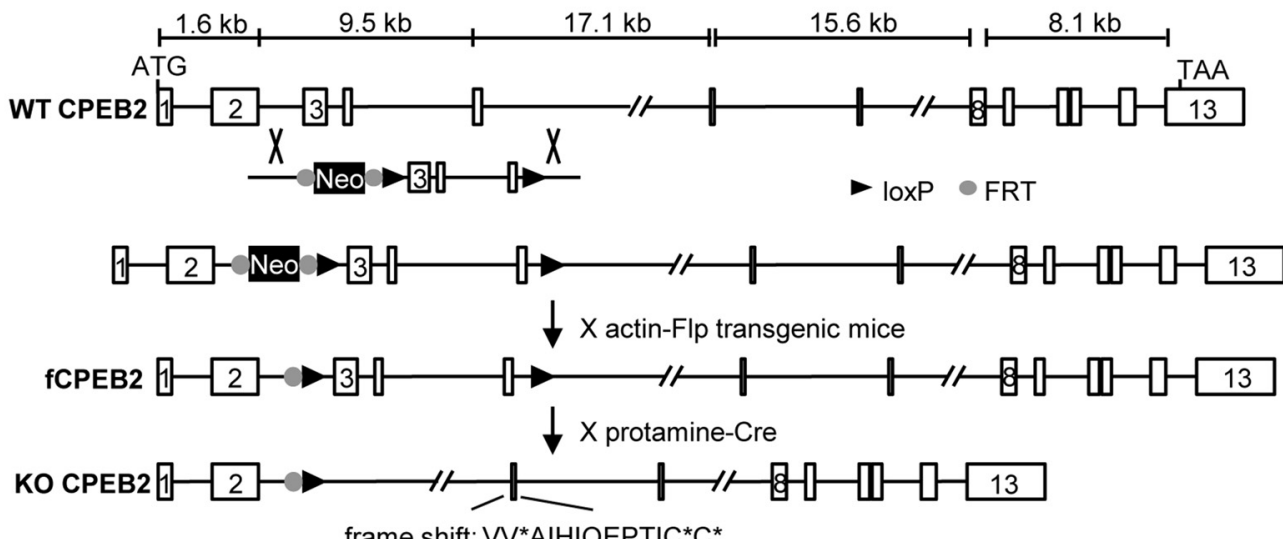

B
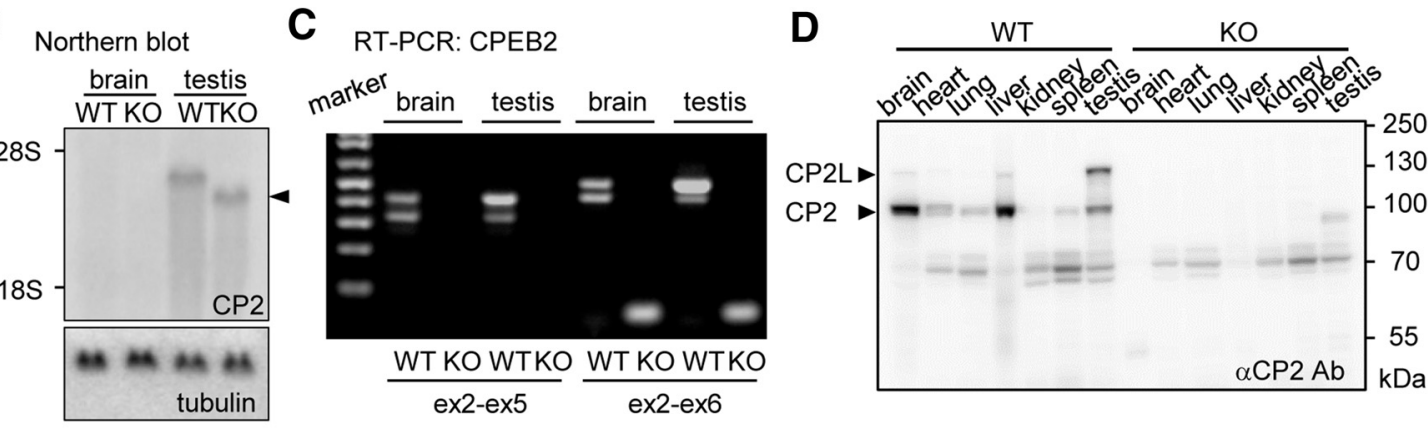

$\mathbf{E}$
\begin{tabular}{llll} 
Age & $+/+\mathrm{WT}$ & \multicolumn{1}{c}{+ /- } & \multicolumn{1}{l}{-/- KO } \\
\hline \hline P0 & $1(12)$ & $2.16(26)$ & $1.25(15)$ \\
P1 & $1(10)$ & $1.80(18)$ & $0.60(6)$ \\
P2 & $1(8)$ & $2.37(19)$ & $0.50(4)$ \\
P3 & $1(18)$ & $2.33(42)$ & $0.39(7)$ \\
P21 & $1(84)$ & $1.92(161)$ & $0.30(25)$ \\
\hline
\end{tabular}

$\mathbf{F}$

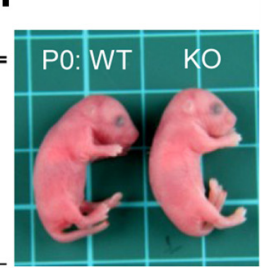

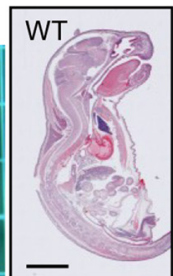

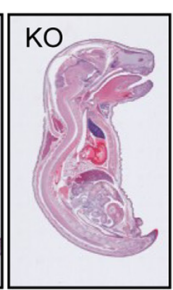

G

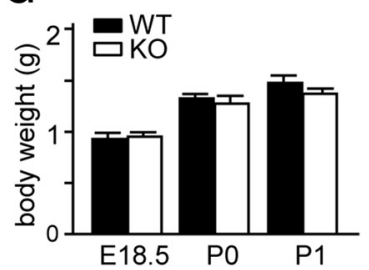

Figure 1. CPEB2 KO mice show high neonatal lethality. A, Schematic illustration of the targeting strategy. The cpeb2 gene consists of 13 exons. Female progenies with the floxed cpeb2 allele (fCPEB2) containing the loxP-flanked exon 3-5 cassette were mated with C57BL/6 males containing a Cre recombinase transgene under the control of a protamine promoter (protamine-cre) to excise exons $3-5$ in sperm to produce the KO allele. Asterisks denote premature termination codon. Male offspring carrying WT or KO ( $-/-$ ) alleles from heterozygous matings were selected for B. $\boldsymbol{B}$, Northern blot analysis with a probe against exons $6-9$ of CPEB2 RNA or $\alpha$-tubulin RNA (loading control). The arrowhead denotes the truncated (PEB2 transcript. C, reverse transcriptioncoupled PCR (RT-PCR) analysis. Brain and testis RNA was reverse-transcribed and PCR-amplified for CPEB2 using the sense primer designed in exon 2 and the antisense primer designed in exon 5 or 6. RT-PCR confirmed the presence of exon 3-5-deleted CPEB2 transcripts in the K0 tissues. The doublet bands resulted from alternative splicing of exon 4 ( 90 bp in length). The inclusion of exon 4 was more prevalent in the testis. D, Western blot analysis. Expression of CPEB2 in the WT and K0 tissues was detected with affinity-purified polyclonal CPEB2 antibody. $\boldsymbol{E}$, The distribution ratios of WT, heterozygous, and KO mice at different ages. Numbers in parentheses denote the number of mice in each group. $\boldsymbol{F}$, The appearance of PO WT and KO littermates and $H \& E-$-stained midline sections of P1 WT and K0 newborns. Scale bar, $2 \mathrm{~mm}$. G, The body weight of E18.5 (WT/K0, $n=18 / 20$ ) embryos, P0 pups (WT/K0, $n=5 / 6$ ), and P1 pups (WT/K0, $n=12 / 11$ ) of WT and K0 genotypes. Data are mean \pm SEM.

$0.02 \mu \mathrm{g}$ of plasmid expressing Renilla luciferase, and $0.74 \mu \mathrm{g}$ of plasmid expressing EGFP or myc-tagged CPEB variants by using Lipofectamine 2000 (Invitrogen). The cells were harvested the next day for dual luciferase assay (Promega) or RNA quantification. The PCR primers were as follows: for firefly luciferase: 5'-TGAGTACTTCGAAATGTCCGTTC-3' and 5'GTATTCAGCCCATATCGTTTCAT-3'; for Renilla luciferase: 5'-GG AGAATAACTTCTTCGTGGAAAC-3' and $5^{\prime}$-GCTGCAAATTCTTC TGGTTCTAA-3'.

\section{Results}

Generation of CPEB2 KO mice that display neonatal lethality To investigate the in vivo functions of $\mathrm{CPEB} 2$, we used the creloxP strategy to generate $\mathrm{CPEB} 2 \mathrm{KO}$ mice in a $\mathrm{C} 57 \mathrm{BL} / 6$ genetic background (Fig. 1A). The littermates from heterozygous crosses were used for all experiments. When exons 3-5 of the cpeb2 gene were excised, the alternative use of the first methionine codon in exon 6 resulted in premature termination. By using a probe against the exon 6-9 region, we found truncated CPEB2 RNA in the $\mathrm{KO}$ testis (Fig. $1 B$ ), suggesting that the premature stop codon in the truncated transcript did not efficiently trigger nonsensemediated RNA decay (Schoenberg and Maquat, 2012). However, Northern blotting was not sensitive enough to detect the CPEB2 RNA signal in the brain. With the more sensitive assay, reverse transcription-coupled PCR, we confirmed the absence of exons 3-5 in CPEB2 RNA in the KO brain and testis (Fig. 1C). Nevertheless, no CPEB2 protein was detected in KO tissues (Fig. 1D). The larger $\mathrm{CPEB} 2$ protein $(\mathrm{CP} 2 \mathrm{~L})$ was translated from a transcript with intron 1 inclusion (NP 787951.2) and expressed predominantly in the testis (Fig. 1D). Thus, we produced a mouse line deficient in CPEB2 protein.

Although we could obtain the $\mathrm{KO}$ mice from heterozygous matings, the number of $\mathrm{KO}$ animals after weaning at P21 was lower than the expected Mendelian inheritance (Fig. 1E), which indicated the lethality associated with ablation of cpeb2. To determine the time of death, we analyzed the ratios in three geno- 


\section{A Echocardiography}

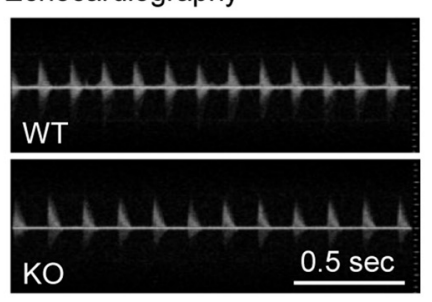

C Plethymography

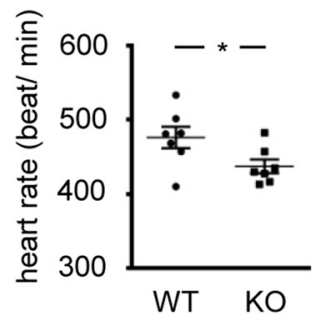

B H\&E staining of P1 heart

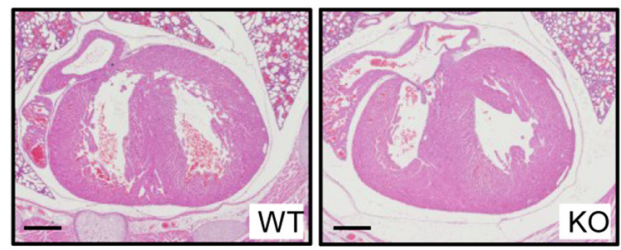

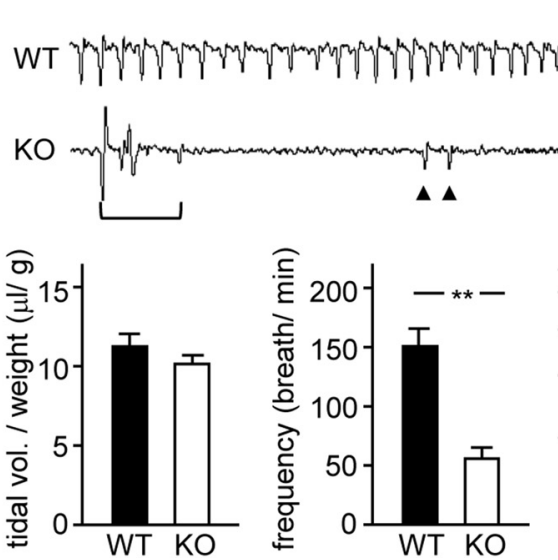

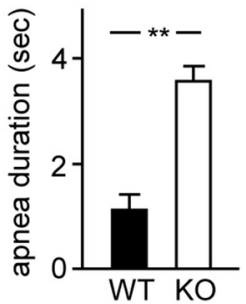

D H\&E staining of $P 1$ lung

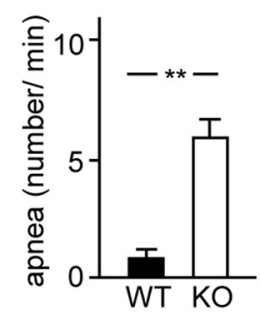

s
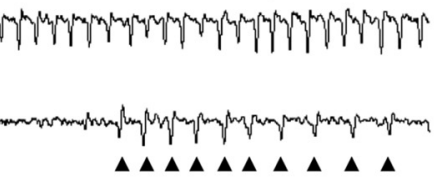

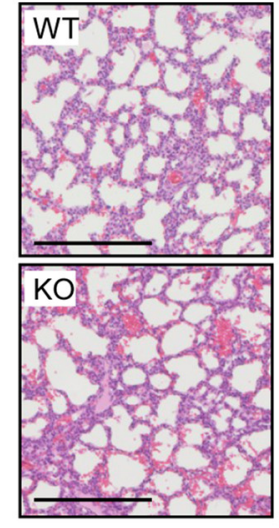

Figure 2. CPEB2 K0 neonates have reduced heart rate and breathing frequency accompanied by apnea. WT and K0 pups at P1 were used. $\boldsymbol{A}$, Doppler ultrasound recording. Representative traces and heart rates (beats/min) in WT ( $n=7)$ and KO $(n=7)$ mice. $\boldsymbol{B}$, H\&E staining of WT and K0 heart sections show normal morphology. $\boldsymbol{C}$, Whole-body plethysmography (WT/K0, $n=12 / 11)$. Representative recorded traces and results of normalized tidal volume (tidal volume/body weight), respiratory frequency, apnea episodes, and duration. ${ }^{* *} p<0.01$, Student's $t$ test. Bracket indicates gasping or body movement and arrowheads denote complete cycle breaths used to determine tidal volume for KO mice. $D$, H\&E staining of lung sections show inflated alveoli of both WT and KO mice. Scale bars, $0.4 \mathrm{~mm}$. Data are mean \pm SEM.

types in P0, P1, P2, and P3 litters. P0 mice showed normal Mendelian distribution and no apparent defects in gross morphology (Fig. $1 F$ ) or body weight (Fig. $1 G$ ). Survival was gradually reduced in $\mathrm{KO}$ mice from $\mathrm{P} 1$ to $\mathrm{P} 3$ (Fig. 1E); most $\mathrm{KO}$ mice died postnatally within $3 \mathrm{~d}$ after birth.

\section{CPEB2 KO neonates show severe respiratory abnormality}

The early death of CPEB2 KO pups motivated us to examine whether CPEB2 controls cardiorespiratory functions to maintain postnatal vitality because cardiac and/or respiratory arrhythmia are possible causes of neonatal death (Shirasawa et al., 2000; Blanchi et al., 2003; Dubreuil et al., 2008; Onimaru et al., 2009; Burgold et al., 2012; Crone et al., 2012; Frank et al., 2012). Using echocardiography and histochemical examination, we found the heart rates in $\mathrm{KO}$ neonates was stable, rhythmic but slightly reduced when compared with their WT littermates (Fig. $2 A$; beats/ min: WT, 476.21 $\pm 15.63 ; \mathrm{KO}, 437.37 \pm 10.01 ; p<0.05)$. There is no obvious defect in gross cardiac morphology (Fig. $2 B$ ) in P1 $\mathrm{KO}$ mice. These results suggest that CPEB2 KO newborns unlikely die of cardiac arrhythmia. Using whole-body plethysmography, we uncovered aberrant respiration patterns in the $\mathrm{KO}$ group and used only detectable breaths (Fig. $2 C$, arrowheads) to determine tidal volume. Other nonrespiratory activities, such as body movement, inside the plethysmography might also disturb the respiratory signal, so the software automatically classified and filtered out these activity-related disturbances (Fig. 2C, bracket). The KO neonates had normal tidal volume (WT, $11.15 \pm 0.81$ $\mu \mathrm{l} / \mathrm{g} ; \mathrm{KO}, 10.07 \pm 0.61 \mu \mathrm{l} / \mathrm{g} ; p=0.3)$ but reduced respiratory frequency (WT, $149.40 \pm 15.02$ breaths/min; KO, $56.84 \pm 10.22$ breaths/min; $p<0.01$ ) and increased apneic episodes (WT,
$0.90 \pm 0.34$ episodes/min; KO, $5.88 \pm 0.74$ episodes $/ \mathrm{min} ; p<$ 0.01 ) and duration (WT, $1.14 \pm 0.28 \mathrm{~s} ; \mathrm{KO}, 3.61 \pm 0.25 \mathrm{~s} ; p<$ $0.01)$. Nevertheless, the gross morphologic features of the WT and $\mathrm{KO}$ lung were similar (Fig. 2D). Cardiac and respiratory functions are critical for neonatal survival immediately after birth. Given that no obvious cardiac abnormality was identified (Fig. 2A), the severe respiratory arrhythmia in CPEB2 KO neonates may contribute to their mortality after birth. Respiration is an intricate process that requires many tissues, such as lung, trachea, diaphragm, intercostal muscle, and ribcage, under the coordinated control of the nervous system to complete a cycle of gaseous exchange. Thus, defective development in any of these tissues or nervous controls may cause abnormal breathing in $\mathrm{KO}$ newborn mice.

\section{Neuron-specific deletion of CPEB2 causes similar respiratory failure}

CPEB2 expression was more abundant in the brain than lung of adult mice (Fig. 1D), so the autonomic nerve system may become uncoordinated with rhythmic respiration in the absence of CPEB2. If so, CPEB2 should be present in the neonatal brain, especially in the brainstem area. As expected, CPEB2 was detected in the brains of E19 embryos and P0 neonates. Unlike CPEB3 and CPEB4 expression, which was distributed more evenly in the brain, CPEB2 level in the brainstem (i.e., pons and medulla) was more abundant (Fig. 3A) and reached a plateau much earlier than in the cortex (Fig. 3B). Thus, CPEB2 likely has a role during perinatal brainstem development. Moreover, CPEB2 was ubiquitously detected in the entire medulla, including the RRG (preBötC and pFRG) and cranial motor nuclei, such as DMNVs, NAs, 
A

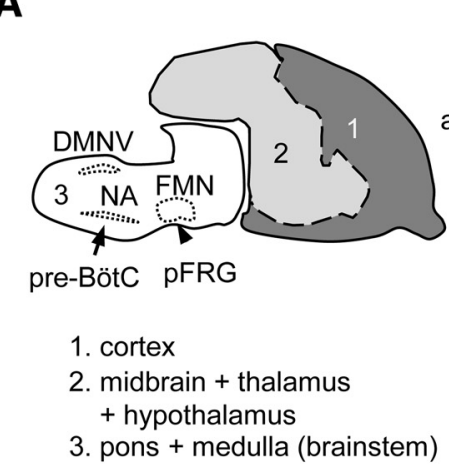

Western blot

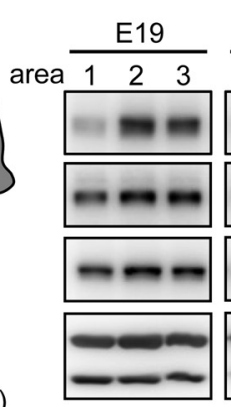

B

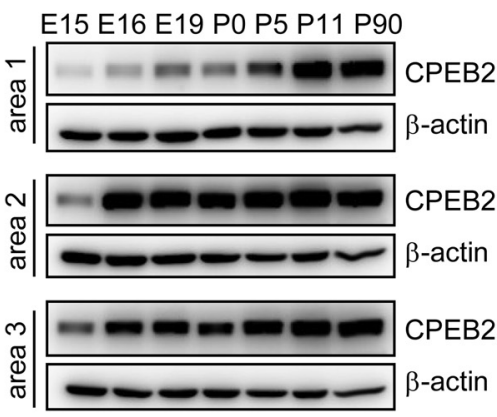

C

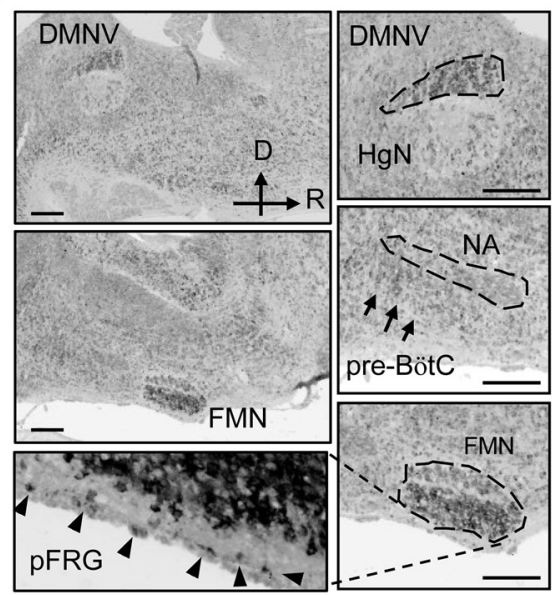

D Plethymography

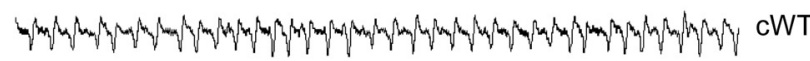
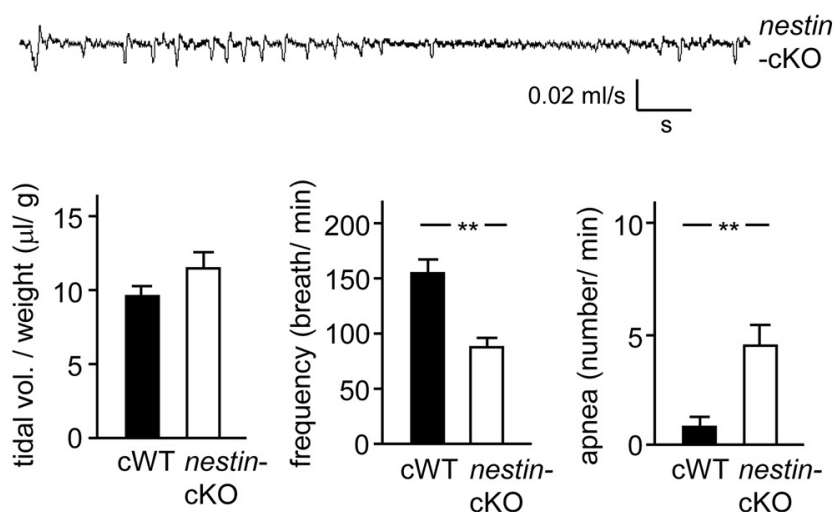

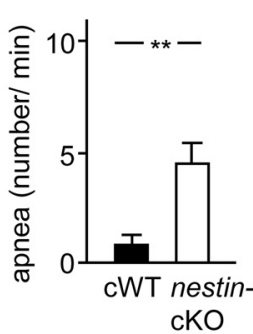

Figure 3. Conditional depletion of $C P E B 2$ in neurons causes respiratory defects. $A$, Schematic outline of a neonatal mouse brain in sagittal plane and respiration-related nuclei in the medulla. The indicated brain regions from E19 and P0 mice were used for Western blot analysis. $\boldsymbol{B}$, The indicated brain regions isolated from embryos and mice of different ages were used for Western blot analysis. C, Immunohistochemistry of CPEB2 in sagittal medullary sections of P0 mice. Scale bars, $0.2 \mathrm{~mm}$. D, Whole-body plethysmographic recordings of respiratory patterns in P1 neonates carrying floxed cpeb2 alleles without (cWT, cpeb2 $2^{\mathrm{f} / \mathrm{f}++/+} ; n=9 ;$; body weight: $1.75 \pm 0.1 \mathrm{~g}$ ) or with nestin-Cretransgene (nestin-cK0, cpeb2 $2^{\mathrm{fff}, \text { nestin-cre/+}} ; n=15 ;$ body weight: $\left.1.64 \pm 0.04 \mathrm{~g}\right)$. Data are mean \pm SEM. ${ }^{* *} p<0.01$, Student's $t$ test.

and FMNs (Fig. 3C). Among these areas, DMNVs and FMNs expressed the most CPEB2 (Fig. 3C). Although FMNs and DMNVs are not in control of generating respiratory rhythms, FMNs and DMNVs innervate the facial musculature and lung, respectively, to maintain normal airway flow during breathing (Kalia and Mesulam, 1980; Strohl, 1985; Bianchi et al., 1995; Fontán et al., 2000; Jordan, 2001; Persson and Rekling, 2011).

Before further investigating which CPEB2-expressed medullary regions account for respiratory failure in the $\mathrm{KO}$ neonates, we first examined whether such respiratory defects could be recapitulated in mice with neuronal depletion of CPEB2. The fCPEB2 (Fig. 1A, cpeb2 ${ }^{\mathrm{f} / \mathrm{f}}$ ) mice were crossed with the nestin-Cre transgenic line. The resulting CPEB2 conditional KO (nestin$\mathrm{cKO}$ ) neonates, with Cre-mediated recombination more limited to the nervous system, were used for plethysmographic recordings. CPEB2 nestin-cKO neonates phenocopied the respiratory defects of the global KO mice. They featured normal tidal volume (cWT, $9.47 \pm 0.39 \mu \mathrm{l} / \mathrm{g}$; nestin-cKO, $11.45 \pm 1.15 \mu \mathrm{l} / \mathrm{g} ; p=0.19$ ), reduced respiratory frequency (cWT, $155.56 \pm 11.82$ breaths/ min; nestin-cKO, $90.26 \pm 7.53$ breaths $/ \mathrm{min} ; p<0.01$ ), and increased apneic episodes (cWT, $0.92 \pm 0.43$ episodes/min; nestincKO, $4.57 \pm 0.74$ episodes/min; $p<0.01$; Fig. $3 D$ ). Thus, the abnormal respiration in the $\mathrm{KO}$ neonates was primarily contributed by the loss of neuronal CPEB2.

\section{CPEB2-deficient RRG is morphologically and} functionally normal

Most gene-modified mice that die of respiratory arrhythmia typically show abnormal morphology of pre-BötC or pFRG, so we wondered whether the respiratory defect in the KO neonates was caused by abnormalities in the RRG. To address this, we first examined morphology by immunostaining the RRG marker, NK1R. The distribution and expression of NK1R in CPEB2deficient pre-BötC and pFRG appeared normal (Fig. 4A; WT/ $\mathrm{KO}, n=2 / 2$; only images from one animal per genotype is shown). Because the outputs from rhythmic bursting of the RRG are merged to $\mathrm{C} 4$ ventral roots and consequently activate phrenic nerves to contract the diaphragm, such activities could be purely monitored in isolated brainstem-spinal cord preparation (Fig. $4 B$ ). The activities of $\mathrm{C} 4$ ventral roots in $\mathrm{KO}$ preparations were stable and rhythmic, with bursting frequencies similar to those in the WT preparations (WT, $12.68 \pm 1.98$ bursts $/ \mathrm{min} ; \mathrm{KO}, 11.3 \pm$ 1.75 bursts/min; $p=0.58$ ). Therefore, the central rhythm generator appears normal in the $\mathrm{KO}$ neonates.

We also examined the (nor)adrenergic system, which modulates rhythm generation (Hilaire, 2006), because several KO mice with respiratory arrhythmia exhibit loss of (nor)adrenergic neurons (Hirsch et al., 1998; Dauger et al., 2001; Qian et al., 2001). Some (nor)adrenergic groups (A5 and A6) are located in the pons, and the others $(\mathrm{A} 1 / \mathrm{C} 1$ and $\mathrm{A} 2 / \mathrm{C} 2)$ are in the 
A

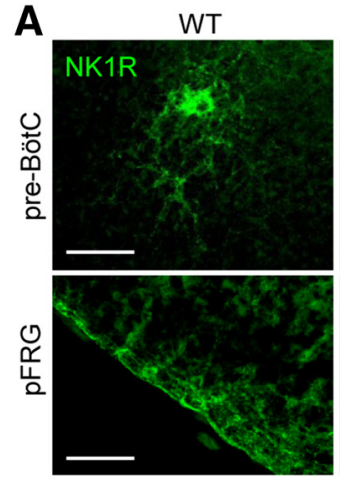

C

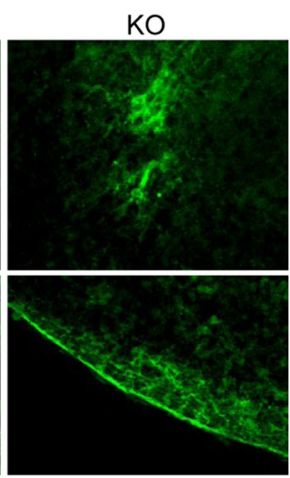

B
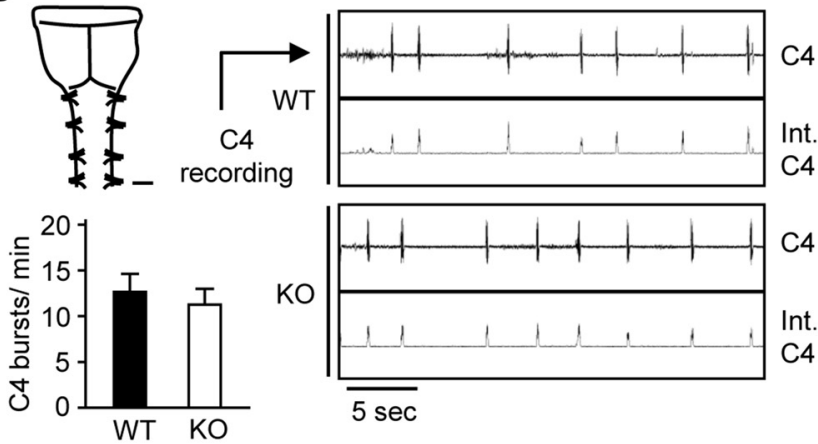

$\mathrm{A} 2 / \mathrm{C} 2$
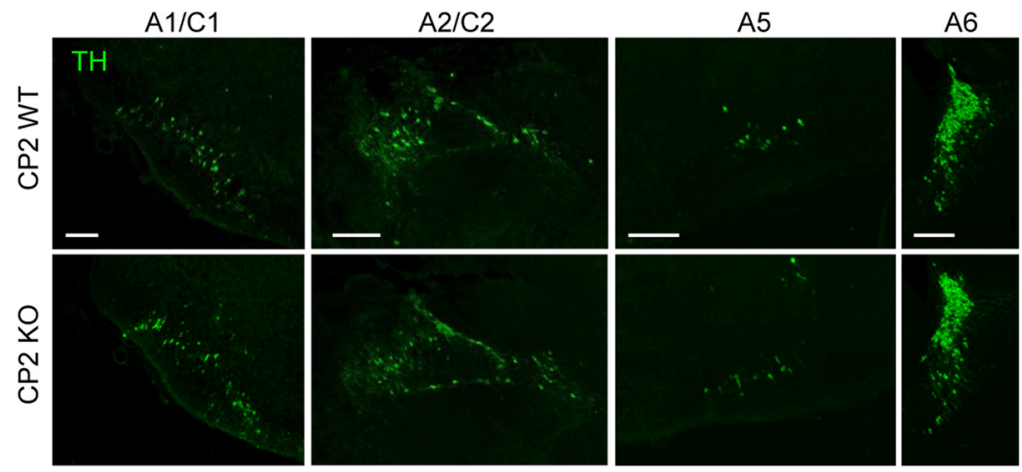

Figure 4. Morphology of the RRG and (nor)adrenergic modulator and activity of C 4 ventral roots are normal in CPEB2 KO neonates. $A$, Coronal medullary sections of P1 WT and K0 mice were immunostained for NK1R to denote pre-BötC and pFRG. $\boldsymbol{B}$, The burst activity in the C 4 ventral roots was recorded with brainstem-spinal cord preparations from P1 WT and K0 mice. Representative raw C4 and integrated C4 (Int. (4) recording traces are shown. The bursting frequencies of the WT $(n=9)$ and KO $(n=10)$ C 4 ventral roots are presented as mean \pm SEM. C, The (nor)adrenergic nuclei in sagittal sections of P1 WT and KO pons-medulla denoted by immunostained signals of TH. Scale bars, $0.2 \mathrm{~mm}$.

medulla (Fig. 4C, illustration). Because the pons is thought to exert an inhibitory effect on inspiration of RRG (Hilaire et al., 1989; Hilaire, 2006), the pontine part has to be removed from the preparation for $\mathrm{C} 4$ recording (Fig. $4 B$ ). However, using the immunostained signal of TH, we observed no apparent difference in pontine and medullary (nor)adrenergic neurons between the WT and KO groups (Fig. $4 C$; WT/KO, $n=2 / 2$; only images from one animal per genotype were shown). Together, these data suggest that the reduced respiratory frequency in the $\mathrm{KO}$ neonates is unlikely a result of defects in RRG or (nor)adrenergic modulators.

\section{No apparent defects in diaphragm NMJs of CPEB2 KO pups}

Proper development of NMJs in the diaphragm is required for normal respiration (Gautam et al., 1996). Because the respiratory failure in CPEB2 KO neonates mainly resulted from the neuronal loss of CPEB2 (Fig. 3D), we then examined NMJs by whole-mount staining of diaphragms from CPEB2 WT and KO littermates. The axon terminals of phrenic nerves and the clusters of nicotinic acetylcholine receptors (AchRs) on the postsynaptic muscle fibers were marked with the immunostained signal of NF-H and fluorophore-labeled $\alpha$-bungarotoxin, respectively. Gross innervation patterns between the WT and KO diaphragms were the same (Fig. 5A, B). All of the quantitative results, including secondary axon length, secondary axon branch number, AchR cluster number, and cluster band width, were indistinguishable between the WT and KO groups (Fig. 5B).

To examine the synaptic transmission of NMJs, spontaneous mEPPs were measured. Both mEPP frequency (WT, $0.98 \pm 0.18 \mathrm{mEPPs} / \mathrm{min} ; \mathrm{KO}, 1.09 \pm 0.19 \mathrm{mEPPs} / \mathrm{min} ; p=$
0.69 ) and amplitude (WT, $2.36 \pm 0.32 \mathrm{mV}$; KO, $2.43 \pm 0.45$ $\mathrm{mV} ; p=0.89)$ recorded from the diaphragms isolated from $\mathrm{P} 1$ WT and KO mice were similar (Fig. 5C). Along with the properly inflated lung in the $\mathrm{KO}$ neonates (Fig. 2D), defects in CPEB2 KO phrenic nerves were not likely the primary causes of respiratory distress.

\section{CPEB2 KO mice respond to hypercapnia but show aberrant respiratory patterns}

Congenital central hypoventilation syndrome (CCHS) can be life threatening. Infants with CCHS display apnea during sleep and lose the adequate response to hypercapnia (Spengler et al., 2001). To test whether the loss of CPEB2 would diminish the hypercapnic ventilatory response, we treated neonatal mice with a hypercapnic mixture $\left(8 \% \mathrm{CO}_{2}\right.$ plus $20 \% \mathrm{O}_{2}$ plus $72 \%$ $\mathrm{N}_{2}$ ). CPEB2 KO mice showed a ventilatory response to hypercapnia (Fig. 6A). Both WT and KO mice showed a comparable and significant increase $(\sim 50-55 \%$ more, $p<0.01)$ in tidal volume under hypercapnic treatment. To our surprise, the respiratory frequency in the $\mathrm{KO}$ mice under hypercapnia could be rescued to the level indistinguishable from that in WT littermates under normoxia (Fig. $6 C$ ) but slightly less than that in the hypercapnia-treated WT mice $(p<0.05)$. Nevertheless, the respiratory patterns in each breath of WT and KO neonates under air or hypercapnia were quite different (Fig. $6 B)$. Thus, we further analyzed other respiratory parameters, including inspiratory and expiratory time as well as peak inspiratory flow (PIF) and peak expiratory flow (PEF) in both WT and KO groups under normoxic or hypercapnic conditions. Because of many undetectable respirations in $\mathrm{KO}$ pups under normoxia, we selected only breaths of the complete 

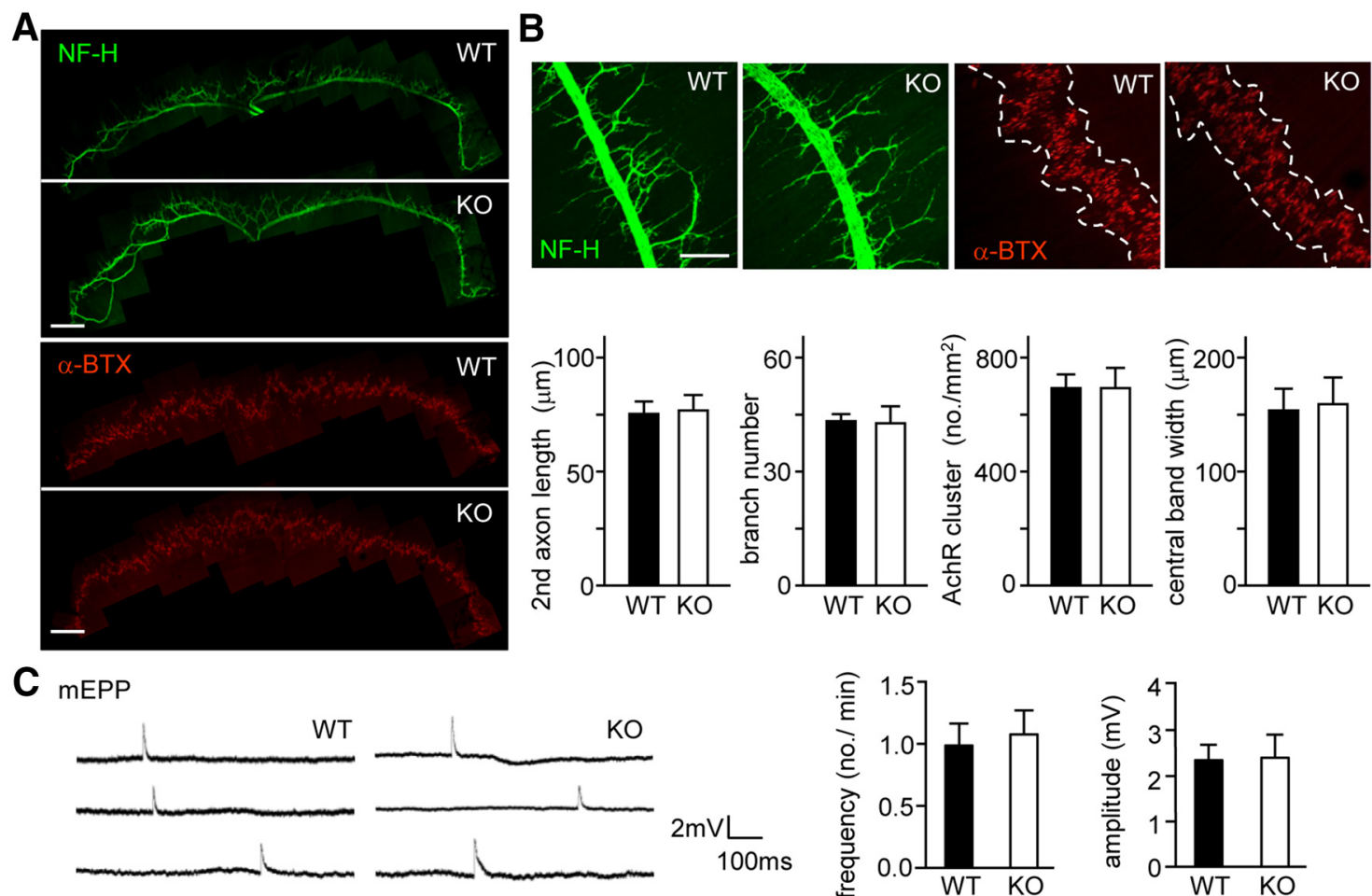

Figure 5. No obvious defect in the NMJ of CPEB2 K0 mice. $A$, Hemidiaphragms from P1 WT and K0 neonates were stained with NF-H antibody (green) and Alexa 594-conjugated $\alpha$-bungarotoxin ( $\alpha$-BTX; red). Scale bar, $0.5 \mathrm{~mm}$. B, Higher magnification showing similar NF-H and AChR staining in diaphragm muscle of WT and KO mice. The secondary axon length and branch number in WT $(n=8)$ and $\mathrm{KO}(n=7)$ phrenic nerves analyzed with the NF-H-immunoreactive signal. AChR cluster number and central band width of AChR endplate zones (marked by white dash lines in the magnified images) analyzed with the $\alpha$-BTX signal (WT/KO, $n=4 / 3$ ). Data are mean \pm SEM. Scale bar, $0.2 \mathrm{~mm}$. C, Representative traces of mEPPs in WT and KO NMJs. Quantitative data show similar frequency and amplitude of mEPPs in KO $(n=8)$ NMJs and in WT $(n=10)$ mice. Data are mean \pm SEM.
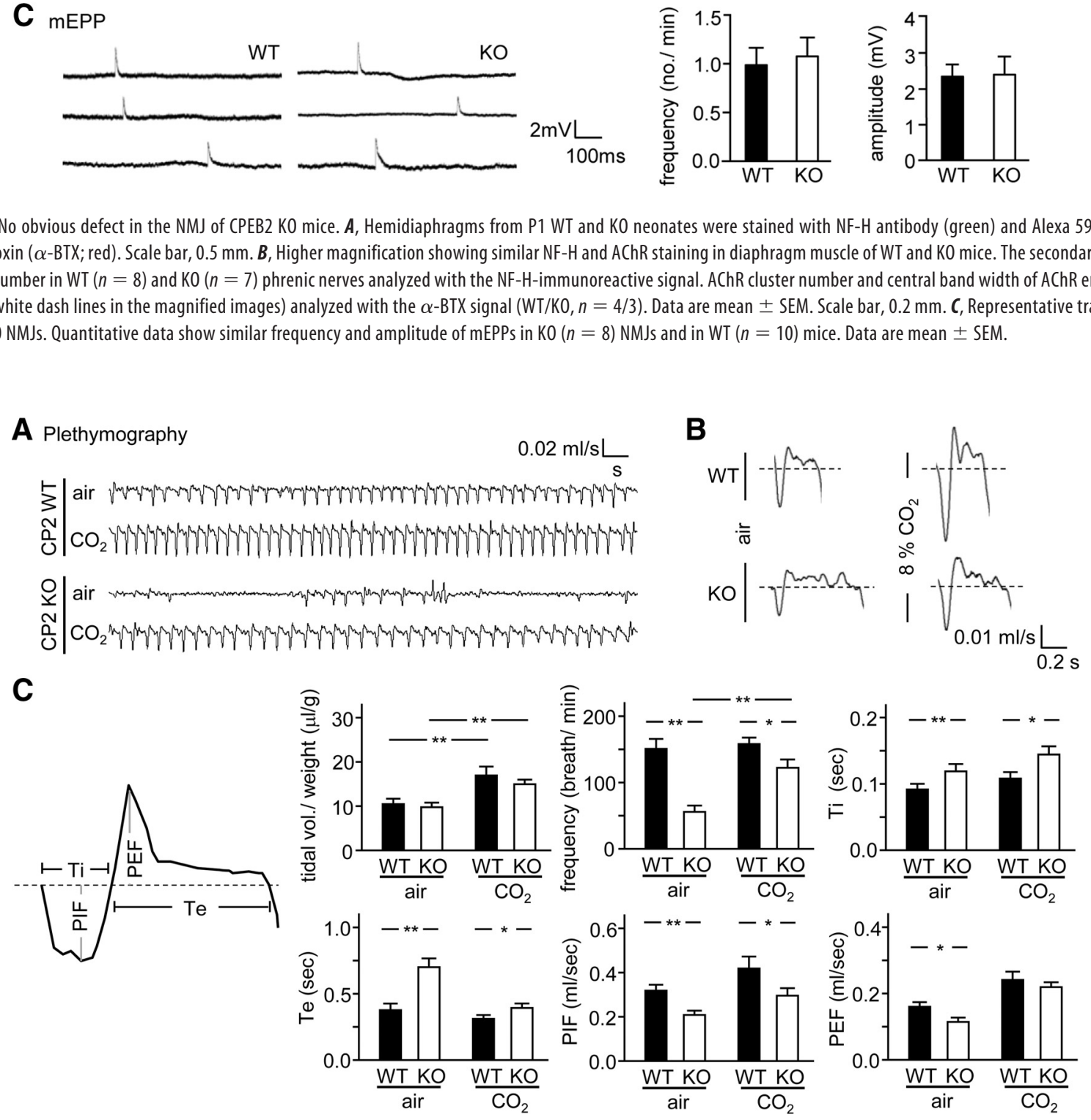

Figure 6. CPEB2 KO mice have ventilatory responses to hypercapnia but show an altered respiratory pattern. $A$, Whole-body plethysmography. Representative breathing traces from P1 WT and K0 neonates under normoxia (air) or hypercapnia $\left(8 \% \mathrm{CO}_{2}\right)$. B , Sample respiratory patterns from these traces. $C$, Data from these recorded traces $\left(\mathrm{WT} / \mathrm{KO}\right.$ : air, $n=12 / 11 ; \mathrm{CO}_{2}$, $n=8 / 8$ ), including normalized tidal volume, respiratory frequency, inspiratory time (Ti), expiratory time (Te), PIF, and PEF, are mean \pm SEM. ${ }^{*} p<0.05$ and ${ }^{* *} p<0.01$, Student's $t$ test. 
cycle for analyses. The results show KO mice had prolonged inspiratory time and expiratory time, regardless of being under normoxia $(p<0.01)$ or hypercapnia $(p<0.05$; Fig. $6 C)$. In addition, PIF $(p<0.01)$ and PEF $(p<0.05)$ were both lower in KO than WT mice under normoxia. However, under hypercapnia, the PEF, but not the PIF, could be rescued ( $p<$ 0.05 ). Although CPEB2 KO neonates exhibited a hypercapnic ventilatory response, their respiratory patterns were still abnormal. Because KO mice have normal RRG and diaphragm NMJs, the apnea phenotype and altered respiratory pattern might be results of other defects, such as increased airway impedance. Nevertheless, it is impossible to directly measure the airway resistance in neonatal mice by an invasive forced oscillation system, so we addressed this possibility further with molecular and cellular approaches.

\section{Elevated ChAT expression in the CPEB2-depleted DMNV leads to increased pulmonary acetylcholine and contraction of bronchial smooth muscle}

The preganglionic parasympathetic neurons of DMNVs and NAs innervate the trachea and pulmonary bronchi (Bennett et al., 1981; Fontán et al., 2000; Jordan, 2001). Because CPEB2 is highly expressed in DMNVs (Fig. $3 C$ ), we then examined these medullary motor nuclei using the cholinergic neuron marker ChAT. The ChAT-immunostaining data indicated that all of the motor nuclei, including DMNVs, hypoglossal nuclei ( $\mathrm{HgNs}), \mathrm{NAs}$, and FMNs, in the KO neonates were still preserved and morphologically normal (Figs. $7 A, B$ ). Notably, the level of ChAT was increased $\sim 48 \%$ in CPEB2-deficient DMNVs (Fig. $7 B ; p<0.01$ ). In contrast, the ChAT levels in NAs and FMNs did not significantly differ between WT and $\mathrm{KO}$ mice (Fig. $7 B$ ). Because the neuron-specific CPEB2 cKO mice mirror the respiratory defect of global $\mathrm{KO}$, we also investigated ChAT expression and found $\sim 20 \%$ increase in level in the nestin-cKO DMNVs (Fig. 7B; $p<0.01$ ). Neurons of the DMNVs have been demonstrated to innervate the lung (Bennett et al., 1981; Fontán et al., 2000) and release acetylcholine to activate muscarinic type 3 receptors on bronchial smooth muscles (Jordan, 2001). Thus, we measured pulmonary acetylcholine in P1 neonates. As expected, the acetylcholine level was significantly increased in the KO lung (WT, $0.4 \pm 0.08$ $\mu \mathrm{M} / \mu \mathrm{g} ; \mathrm{KO}, 0.82 \pm 0.16 \mu \mathrm{M} / \mu \mathrm{g} ; p<0.05)$ and in the nestincKO lung (cWT, $0.37 \pm 0.06 \mu \mathrm{M} / \mu \mathrm{g}$; nestin-cKO, $0.99 \pm 0.23$ $\mu \mathrm{M} / \mu \mathrm{g} ; p<0.05$; Fig. $7 C$ ).

Because the airway postganglionic neurons are also cholinergic, we examined whether upregulated ChAT expression occurs in those neurons. The postganglionic neurons near the dorsal trachea and medial bronchi (Langsdorf et al., 2011) were immunolabeled with ChAT and the pan-neuronal marker Tuj1. No significant difference in ChAT expression was found between $\mathrm{WT}$ and $\mathrm{KO}$ postganglionic neurons (Fig. $7 D ; p=0.65)$, so aberrant ChAT expression is confined to central preganglionic parasympathetic neurons. To evaluate whether the pulmonary acetylcholine increase enhances the contraction of smooth muscle around bronchi, we monitored the Ser 19 phosphorylation of myosin light chain 2 (p-Mlc2) since this phosphorylation by myosin light chain kinase promotes myosin ATPase activity and smooth muscle contraction (Hashimoto et al., 2006; Zhang et al., 2010; Kudo et al., 2013). Around bronchi, the p-Mlc2 signal in the smooth muscle, denoted by $\alpha \mathrm{SMA}$ staining, was significantly elevated in the $\mathrm{KO}$ lung (Fig. $7 E ; p<0.01$ ). CPEB2 $\mathrm{KO}$ mice are thus expected to show hyperactivated parasympathetic signaling-associated bronchoconstriction because of elevated acetylcholine release from DMNVs. Moreover, the decreased cardiac rhythm (Fig. $2 A$ ) also supports elevated parasympathetic signaling in $\mathrm{KO}$ neonates. Similar findings were reported in $o b / o b$ adult mice (Arteaga-Solis et al., 2013) whose elevated DMNV cholinergic signaling promoted bronchoconstriction but mildly reduced $(\sim 10 \%)$ heart rate (Arteaga-Solis et al., 2013).

\section{Cholinergic neuron-restricted loss of CPEB2 is sufficient to cause obstructive airway-associated apnea}

Among the respiration-related areas investigated so far, the elevated ChAT expression in the DMNV appears to be the most evident change consistent with respiratory abnormality in the $\mathrm{KO}$ pups. Nevertheless, we cannot exclude the possibility that the respiratory nuclei of normal morphology (Fig. 4) may have aberrant neuronal activity to cause dysregulation of the respiratory network. To further clarify this issue and retain CPEB2 expression in RRG and (nor)adrenergic nuclei, we crossed fCPEB2 mice with the chat-Cre transgenic line to selectively ablate the cpeb2 gene in cholinergic neurons. The CPEB2 $2^{\mathrm{f} / \text {,chat-Cre/+ }}$ neonates (chat-cKO) exhibited the same respiratory defects as global KO pups but with wide individual variation in severity; on average, they still showed reduced respiratory frequency (cWT, $203.79 \pm$ 8.06 breaths/min; chat-cKO, $168.2 \pm 16.37$ breaths $/ \mathrm{min} ; p<$ 0.05 ) and increased apnea episodes (cWT, $0.38 \pm 0.16$ episodes/ min; chat-cKO, $1.74 \pm 0.73$ episodes/min; $p<0.05$; Fig. $8 A$ ). Molecular changes, including elevated ChAT expression in DMNVs (Fig. $8 B$ ) and pulmonary acetylcholine level (Fig. 8C; cWT, $0.38 \pm 0.07 \mu \mathrm{M} / \mu \mathrm{g} ;$ chat-cKO, $0.62 \pm 0.1 \mu \mathrm{m} / \mu \mathrm{g} ; p<$ $0.05)$, were also recapitulated in the chat-cKO mice, indicating that the apnea phenotype was partly due to the augmented cholinergic signaling from DMNVs. To further support our findings, we used an invasive forced oscillary system (Albacker et al., 2013) to directly measure airway resistance in anesthetized cWT and chat-cKO adult mice. The result showed methacholine-induced airway reactivity was significantly higher in chat-cKO adult mice (Fig. $8 D ; p<0.05$ ). Thus, cholinergic deficiency of CPEB2 is sufficient to induce airway hyper-reactivity.

\section{Inhalation of an anticholinergic bronchodilator mitigates obstructive airway-associated apnea in $\mathrm{KO}$ and chat-cKO neonates}

If the apnea episodes in CPEB2 $\mathrm{KO}$ and cKO pups result from elevated parasympathetic signaling-induced bronchoconstriction, administration of an anticholinergic bronchodilator would be expected to ameliorate the consequential obstructive apnea. Thus, global KO and chat-cKO P0 pups were exposed to nebulized tiotropium (a long-acting anticholinergic bronchodilator) for $3 \mathrm{~min}$ and then underwent whole-body plethysmography $24 \mathrm{~h}$ later. Although nebulized tiotropium administration significantly reduced apnea frequency in $\mathrm{KO}$ (Fig. 9A; KO, $6.68 \pm 0.66$ episodes/min; KO plus nebulized tiotropium, $3.74 \pm 1.17$ episodes/min; $p<0.05$ ) and chat-cKO pups (Fig. 9B; chat-cKO, $1.89 \pm 0.78$ episodes/min; chat-cKO plus nebulized tiotropium, $0.19 \pm 0.09$ episodes $/ \mathrm{min} ; p<0.05)$, the pharmacological rescue effect was only partial in KO mice when compared with their WT littermates (Fig. 9A; WT, $0.65 \pm 0.43$ episodes/min; KO plus nebulized tiotropium, $3.74 \pm 1.17$ episodes/min; $p<0.01$ ). Thus, hyperactivated parasympathetic signaling-induced bronchoconstriction likely accounts for some but not all respiratory abnormalities in CPEB2 KO newborn mice. 
A

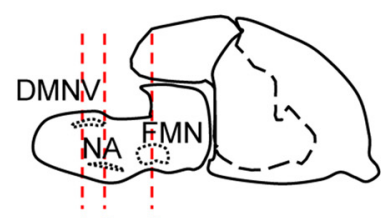

123

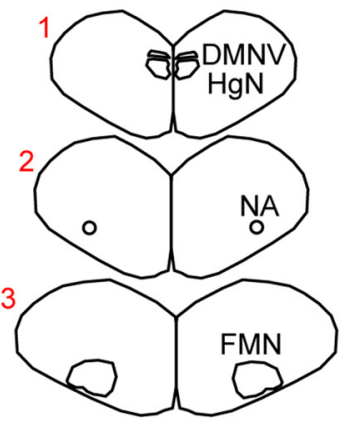

C

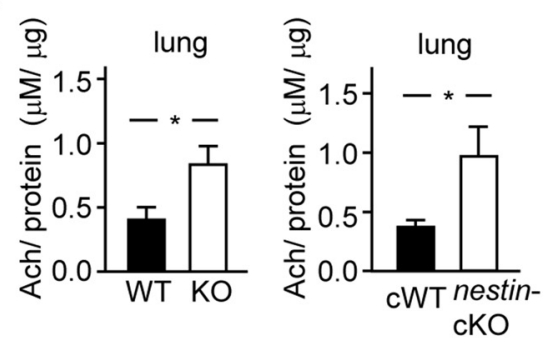

B
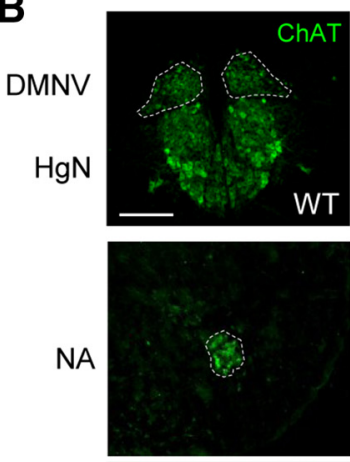

\section{.}
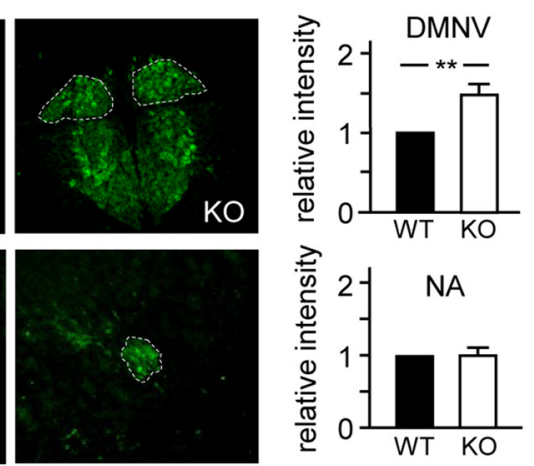

FMN
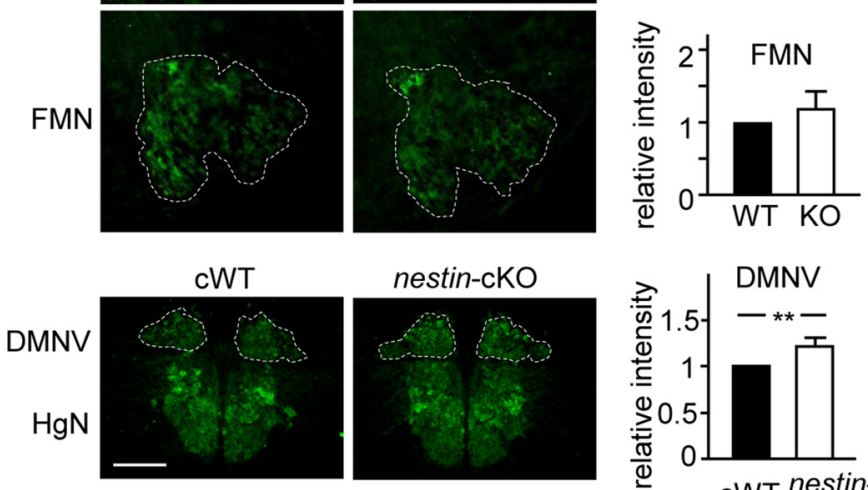

nestin-cKO

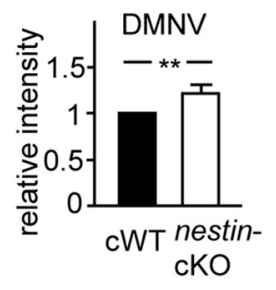

D Post-ganglia

WT
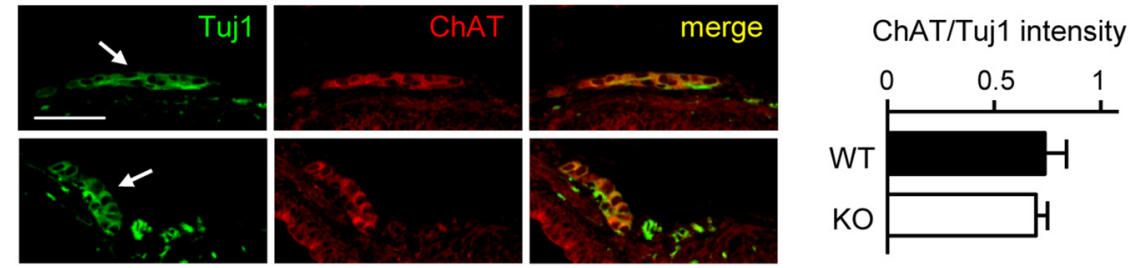

$\mathbf{E}$
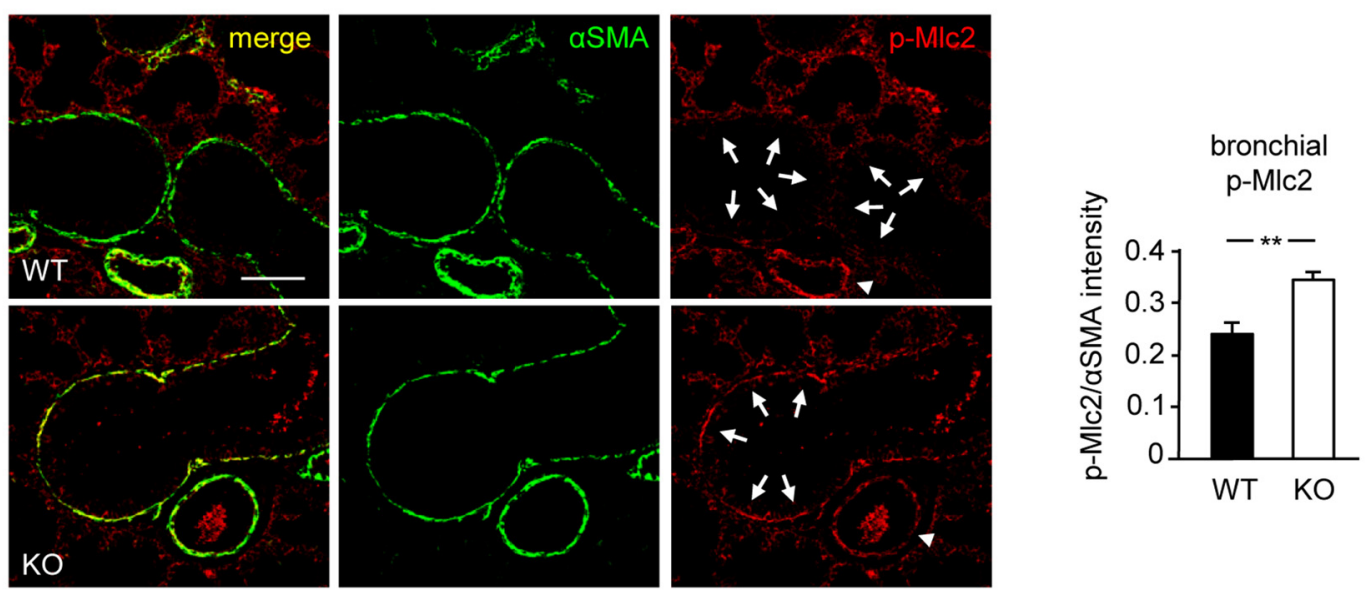

Figure 7. CPEB2 KO neonates show elevated ChAT expression in DMNVs and increased pulmonary content of acetylcholine. A, Selected motor nuclei, DMNVs, HgNs, NAs, and FMNs, are illustrated for their relative location in the medulla of both sagittal and coronal planes. $\boldsymbol{B}$, Representative ChAT-immunostained images from coronal sections of the medulla. The immunofluorescence intensities of ChAT in DMNVs (WT/KO, $n=7 / 7$; cWT/nestin-cKO, $n=6 / 6$ ), NAs (WT/K0, $n=7 / 7$ ), and FMNs (WT/K0, $n=5 / 5$ ) are expressed as a relative ratio with the signal in the WT or cWT tissue arbitrarily set to 1 . Scale bars, $0.2 \mathrm{~mm}$. C, The lungs isolated from P1 WT/KO $(n=8 / 8)$ or cWT/nestin-cKO $(n=11 / 9)$ neonates were used to measure acetylcholine level normalized to the amount of total protein. $D$, Postganglionic neurons ( $\mathrm{WT} / \mathrm{KO}, n=5 / 7$ ) in dorsal trachea and medial bronchi indicated by arrows were immunolabeled with Tuj 1 and ChAT antibodies. The quantified result is expressed as the mean fluorescent intensity of ChAT normalized by that of Tuj1. Scale bars, $0.05 \mathrm{~mm}$. $\boldsymbol{E}$, The P1 WT/K0 ( $n=5 / 5)$ lungs were used for immunostaining of $\alpha$ SMA and p-MIC2 to mark smooth muscle and muscle contraction status, respectively. Bronchial and vascular smooth muscles were denoted by arrows and arrowheads, respectively. The quantified relative signal is presented as the fluorescent intensity of p-Mlc 2 normalized by that of $\alpha$ SMA. Scale bars, $0.1 \mathrm{~mm}$. All data are mean \pm SEM. ${ }^{*} p<0.05$ and ${ }^{* *} p<0.01$, Student's $t$ test. 
A

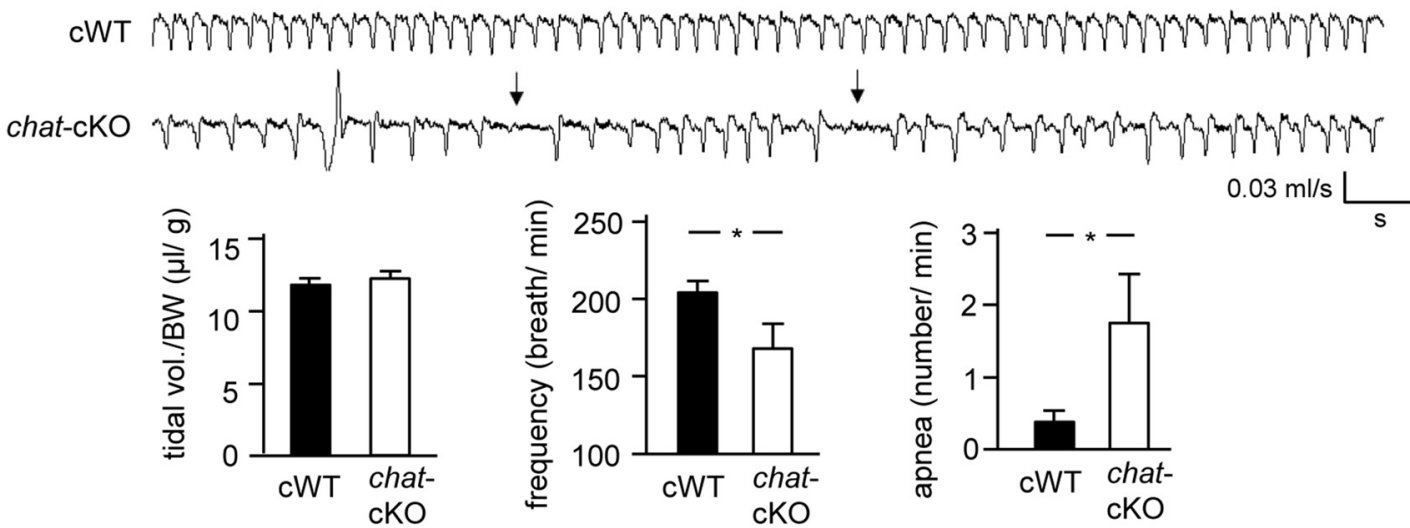

B

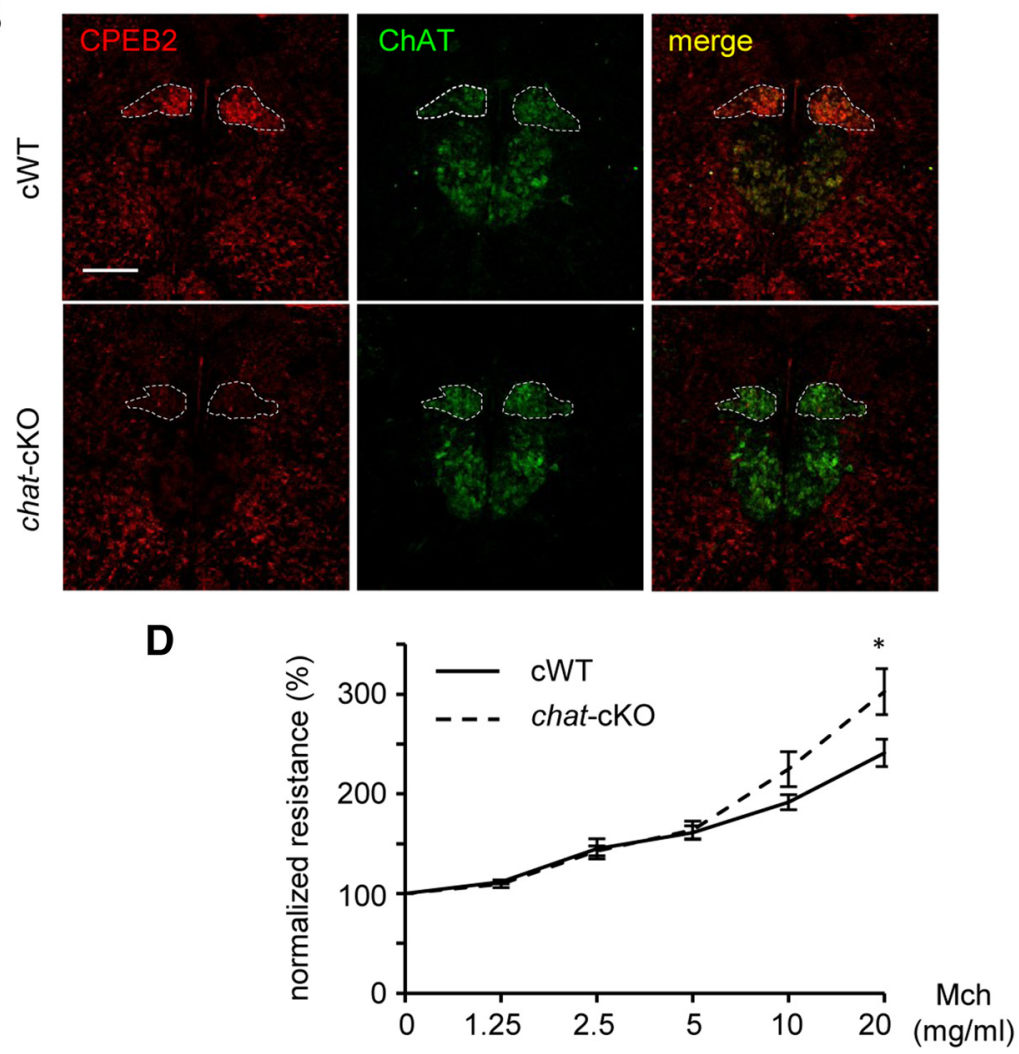

Figure 8. Deletion of CPEB2 in cholinergic neurons causes respiratory apnea. $A$, Whole-body plethysmographic recordings of respiratory patterns in $\mathrm{P} 1 \mathrm{cWT}\left(\mathrm{cpeb2}{ }^{\mathrm{f} / \mathrm{f},+/+} ; n=16 ;\right.$ body weight, $1.75 \pm 0.06 \mathrm{~g}) /$ chat-cKO (cpeb2 $2^{\mathrm{f} / \text {, chat-cre/+ }} ; n=12 ;$ body weight, $\left.1.64 \pm 0.07 \mathrm{~g}\right)$ neonates. Arrows denote apneic episodes. $\boldsymbol{B}$, Representative ChAT-immunostained and (PEB2-immunostained images from coronal sections of cWT and chat-cK0 medulla. Scale bar, $0.2 \mathrm{~mm}$. C, The lungs isolated from P1 cWT $(n=8)$ and chat-cKO $(n=7)$ neonates were used to measure acetylcholine level normalized to the amount of total protein. $\boldsymbol{D}$. The airway hyper-reactivity of adult cWT $(n=7)$ and chat-cKO mice $(n=8)$ evoked by increasing doses of methacholine (Mch) was measured by the invasive plethysmography. Normalized resistances were calculated with that in the baseline $(M c h, 0)$ arbitrarily set to $100 \%$. Data are mean \pm SEM. ${ }^{*} p<0.05$, Student's $t$ test in $A$ and $C$; two-way ANOVA in $\boldsymbol{D}$.

\section{CPEB2 binds to ChAT mRNA and represses its translation} Because CPEB2 functions as a translational repressor, the elevated ChAT expression in the CPEB2-deficient DMNV could be caused by translational upregulation. ChAT RNA was also one of the CPEB2-bound mRNAs found in the RIPmicroarray data. To confirm this result, we repeated the RNA immunoprecipitation experiment using brainstem lysates and found a twofold increase in the level of ChAT mRNA pulled down by CPEB2 IgG $(p<0.01$; Fig. 10A). To investigate whether CPEB2 regulates translation of ChAT mRNA through its $3^{\prime}$-UTR, we performed the luciferase reporter assay in Neuro-2a neuroblastoma cells (Fig. 10B). Only the full-length but not the C-terminal RNA-binding domain (lacking the re- pression motif) of CPEB2 could repress the reporter protein but not RNA levels (Fig. 10B). Together, these results indicate that CPEB2 binds to the $3^{\prime}$-UTR of ChAT mRNA and represses its translation to downregulate cholinergic transmission in the lung and confine parasympathetic tone-activated bronchoconstriction (Fig. 10C).

\section{Discussion}

In this study, we generated CPEB2 $\mathrm{KO}$ mice whose neonatal lethality identifies the regulatory role of CPEB2 in respiration. Because CPEB2 is differentially but widely expressed and respiration is a very intricate process, we first used nestin-Cre CPEB2 cKO mice to confirm that the respiratory defect in the 
A
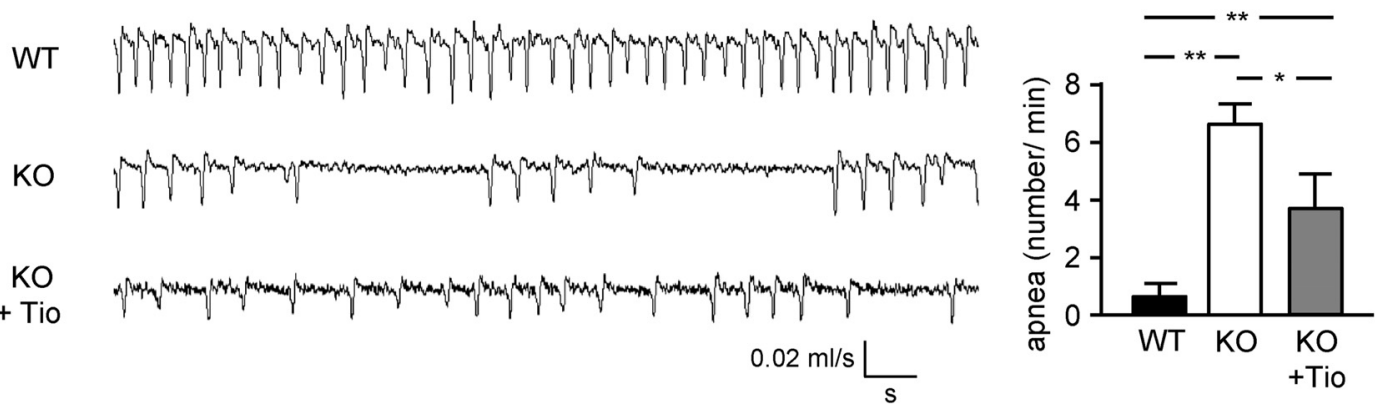

B

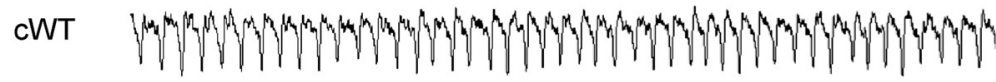

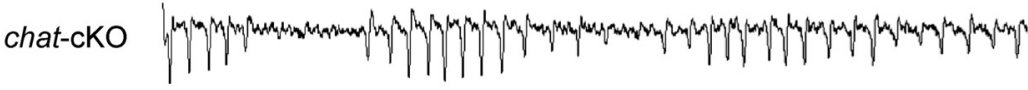

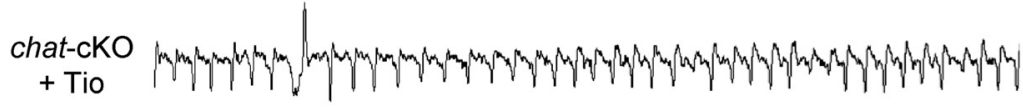

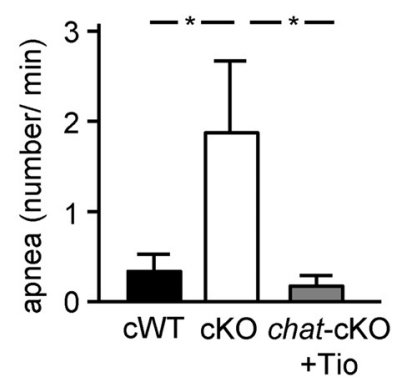

Figure 9. The use of an inhaled anticholinergic bronchodilator mitigates apnea phenotype in CPEB2 KO and chat-cKO neonates. $A$, Whole-body plethysmographic recordings of respiratory patterns in WT $(n=9), K O(n=10)$, and KO $(n=6)$ neonates given nebulized tiotropium (Tio). $\boldsymbol{B}$, Whole-body plethysmographic recordings of respiratory patterns in cWT $(n=14)$, chat-cKO $(n=11)$, and chat-cKO $(n=8)$ neonates rescued with Tio. Data are mean \pm SEM ${ }^{*} p<0.05$ and ${ }^{* *} p<0.01$, Student's $t$ test.

A

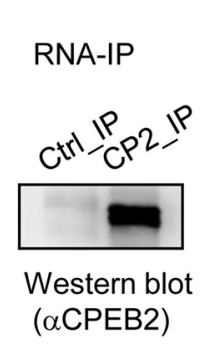

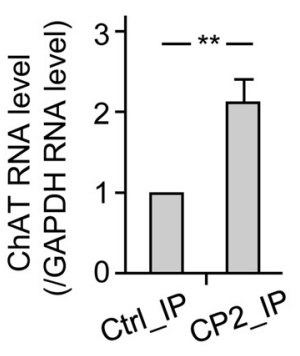

B Reporter assay

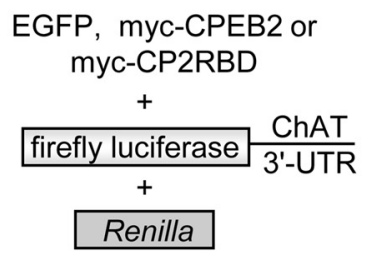

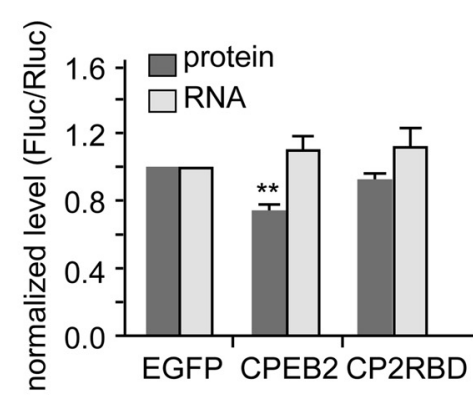

\section{C}

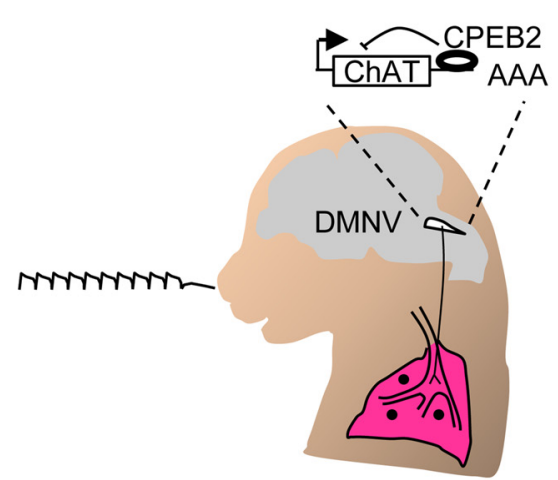

WT
- Acetylcholine

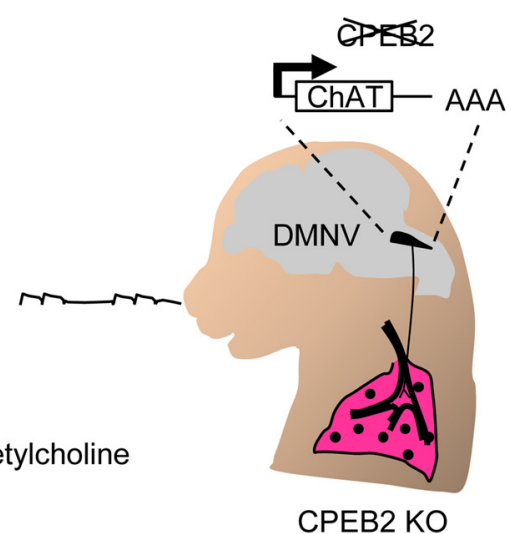

Figure 10. CPEB2 represses the translation of ChAT mRNA through its $3^{\prime}$-UTR. A, RNA-immunoprecipitation (RNA-IP). Neonatal brainstem lysates were precipitated with control and CPEB2 lgG. Reverse-transcribed quantitative PCR of ChAT mRNA levels in immunoprecipitates expressed as a relative ratio to the nontarget control, GAPDH RNA. $\boldsymbol{B}$, Reporter assay. Neuro-2a cells were transfected with the reporter plasmids, firefly luciferase appended to the mouse ChAT 3' -UTR (FLuc), and Renilla luciferase (RLuc), along with the plasmid expressing myc tag, full-length or the RNA-binding domain (CP2RBD) of CPEB2. Cells were harvested to determine the protein (by measuring the activity) and RNA levels of luciferases. Three independent experiments were performed. Data are mean \pm SEM. ${ }^{*} p<0.05$ and ${ }^{* *} p<0.01$, Student's test. C, Schematic model of CPEB2-controlled neonatal respiration. CPEB2 binds to the $3^{\prime}$-UTR of ChAT mRNA and represses its translation to confine acetylcholine synthesis and DMNV-activated bronchoconstriction. Elevated ChAT RNA translation in the KO DMNV produces excess acetylcholine to overactivate bronchoconstriction, leading to airway obstruction and apnea phenotype. 
A

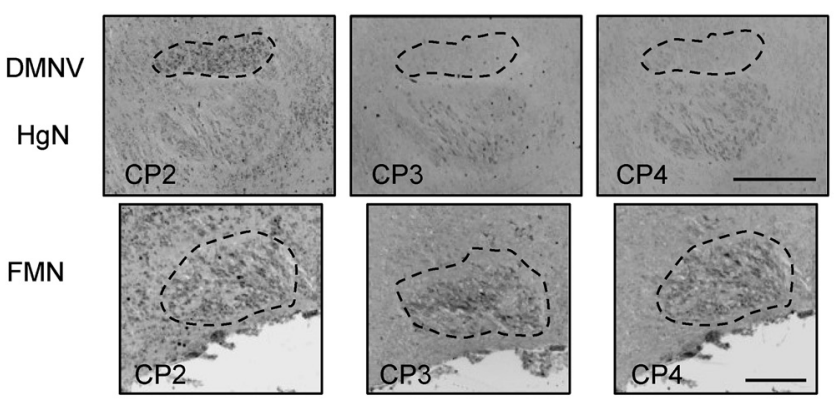

B Reporter assay
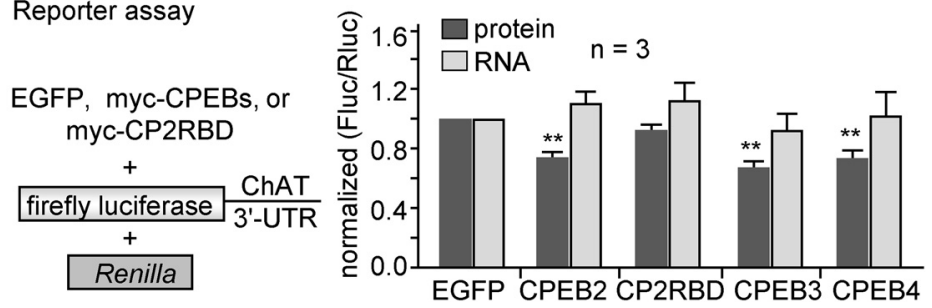

Figure 11. CPEB2 but not $C P E B 3$ and $C P E B 4$ is highly expressed in the DMNV. $A$, Immunohistochemistry of CPEB2-CPEB4 in the sagittal medullary sections of P0 mice. Scale bars, $0.2 \mathrm{~mm}$. $\boldsymbol{B}$, Reporter assay. Neuro-2a cells were transfected with the reporter plasmids, firefly luciferase appended to the mouse ChAT $3^{\prime}$-UTR (FLuc), and Renilla luciferase (RLuc), along with the plasmid expressing various myc-tagged CPEBs. The cells were harvested to determine the protein and RNA levels of luciferases. All error bars indicate SEM. ${ }^{* *} p<0.01$, Student's $t$ test.

$\mathrm{KO}$ neonates is primarily caused by neuronal loss of CPEB2. The apneic phenotype led us to examine the morphology and function of RRG and diaphragm NMJs as well as the RRGmodulating (nor)adrenergic systems, but we found no obvious abnormalities in these areas. Hypercapnia evidently rescued the $\mathrm{KO}$ neonate's apnea, which redirected our thinking about the plethysmographic measurement. A plethysmograph is an instrument for measuring pressure changes within the chamber that are due to inspired air humidified and heated by an animal's lung during breathing. We surmise that the apneic episodes under normoxia may be due in part to the detection limit of our plethysmograph since the pressure change in the KO pups at any given time during inspiration and expiration should be subtle with obstructed airways. Moreover, $\mathrm{CO}_{2}$ is a natural bronchodilator (Astin et al., 1973) since hypercapnia has been shown to relax airway smooth muscles in several mammalian species (Duane et al., 1979; Twort and Cameron, 1986). Therefore, in addition to the $\mathrm{CO}_{2}$-evoked central chemosensory response, the bronchodilation effect of $\mathrm{CO}_{2}$ may also contribute to rescuing the apneic phenotype of the KO pups.

Notably, specific depletion of CPEB2 in cholinergic neurons of chat-cKO pups recapitulates obstructive airway-associated respiratory apnea found in the global $\mathrm{KO}$ and nestin-cKO neonates, but the degree of severity is much reduced. Moreover, the apnea phenotype in global KO pups is only partially rescued by nebulized tiotropium inhalation (Fig. 9A), suggesting that noncholinergic neurons or even non-neuronal tissues may also contribute to aggravate respiratory abnormality in the absence of CPEB2. For example, the Kölliker-Fuse (KF) nucleus in pons, which was removed from our preparations for $\mathrm{C} 4$ activity recording (Fig. $4 B$ ), gate the postinspiratory phase of respiration and regulates upper-airway musculature. An injection of glutamate into the KF nucleus triggers a transient postinspiratory apnea (Dutschmann and Herbert, 2006). Possibly, CPEB2, in addition to playing a role in the lower-airway anomalies identified in this study, may also function in pontine nuclei to regulate respiratory pattern and upper-airway resistance. To test this possibility, the working heart-brainstem preparation system, which includes the pontine circuits and sensory inputs, needs to be established to monitor pontine respiratory activity $(\mathrm{Pa}-$ ton, 1996). However, such a sophisticated setup remains technically challenging to perform on P1 mice.

In addition to signaling on heart and lung, the DMNV contains many preganglionic neurons that project to postganglionic neurons innervating the gastrointestinal (GI) tract (for review, see Browning and Travagli, 2014). Vagal efferents to the GI tract comprise not only excitatory but also inhibitory pathways. The excitatory pathway consists of preganglionic cholinergic neurons synapsing onto postganglionic cholinergic neurons. Meanwhile, the inhibitory pathway is composed of two kinds of preganglionic neurons. One type is cholinergic neurons synapsing onto postganglionic nonadrenergic, noncholinergic (NANC) neurons. The other type is nitrergic neurons synapsing onto NANC neurons. Although the elevated ChAT expression in CPEB2-KO DMNVs possibly affects GI motility or secretory function, altered GI function probably does not lead to respiratory defect and early lethality. Thus, in the present study, we did not focus on investigating whether CPEB2 signaling through the DMNV regulates GI function.

We wondered why lack of CPEB2 affected ChAT expression only in the DMNV but not in other motor nuclei. Because CPEB2 binds to RNA of the same sequence specificity with CPEB3 and CPEB4 (Huang et al., 2006), both of which can also function as a translational repressor in vivo (Chao et al., 2013; Hu et al., 2014), we speculated whether the differential presence of other family members might compensate for loss of CPEB2 in some but not all motor nuclei. The immunostaining results showed that CPEB2 but not CPEB3 or CPEB4 is uniquely expressed in the DMNV. In contrast, all three CPEBs were expressed in HgNs and FMNs (Fig. $11 A$ ). In the reporter assay, CPEB 3 and CPEB4 could also repress the luciferase reporter appended with the ChAT 3 '-UTR sequence (Fig. 11B). Thus, the expression of ChAT in DMNVs is likely regulated only by CPEB2.

Although the trachea and lung in adult rats are innervated by neurons from the NA more than the DMNV (Haxhiu et al., 1993; Hadziefendic and Haxhiu, 1999; Fontán et al., 2000), some studies report that electrical and chemical activation of the DMNV decreases respiratory frequency and induces apnea in anesthetized rats (Marchenko and Sapru, 2000; Zhang et al., 2006). Because the DMNV is ventrally located next to the nucleus tractus solitarius (NTS), it remains possible that such respiratory changes upon stimulation of the DMNV might be partly caused by activating the nearby neurons in the NTS. Nevertheless, a recent study showed that leptin signaling through its receptor (lepr) in the DMNV inhibited vagus nerve-activated bronchoconstriction. Pulmonary acetylcholine level and airway resistance were increased in leptindeficient mice as well as diet-induced lepr-desensitized obese mice via enhanced parasympathetic signaling (Arteaga-Solis et al., 2013). Similarly, another study also demonstrated that 
elevated insulin signaling through cholinergic neurons in the DMNV and NA induced airway hyper-reactivity in obese mice (Leiria et al., 2015). To our knowledge, our studies represent the first animal model of defective DMNV-regulated respiration in neonatal mice.

DMNV anomalies have been detected in brainstem specimens of infants who died of SIDS (Bejjani et al., 2013). The causes of SIDS are complicated and remain unclear, but many reports indicate that one major cause may be abnormal cardiorespiratory reflexes (Kahn et al., 1983; Schechtman et al., 1996; Kato et al., 2000; Machaalani and Waters, 2014). Although the increased ChAT expression in the DMNV of CPEB2 KO mice is not consistent with the decreased ChAT level found in clinical SIDS cases (Mallard et al., 1999), dysregulated (either too high or too low) DMNV-governed parasympathetic signaling may be detrimental to respiratory function. In fact, smoking during pregnancy is associated with increased risk of SIDS (Mitchell et al., 1993). Prenatal exposure to carbon monoxide (i.e., a major component of cigarette smoke) to mimic maternal smoking during pregnancy increased ChAT immunoreactivity in the DMNV of fetal guinea pig (Tolcos et al., 2000).

In this study, we demonstrate that CPEB2 is required for neonatal respiration by governing ChAT synthesis and parasympathetic transmission in the DMNV to keep the airway unimpeded. $\mathrm{CPEB} 2 \mathrm{KO}$ mice are born alive but most die before weaning, whereas surviving mice live $\geq 12$ months without obvious physical problems. While no clear diagnostic markers currently exist, several SIDS-related polymorphisms have been identified, with most in genes associated with neuronal signaling, cardiac contraction, and inflammatory response (Fleming et al., 2015; Mitchell and Krous, 2015). The genetic polymorphisms of SIDS likely predispose infants to death in critical situations since most SIDS deaths are associated with sleep. Although we are unable to determine whether CPEB2 KO newborns die during sleep, we speculate that neonatal mice or babies with aberrant DMNV-directed commanded parasympathetic signaling are more vulnerable when activity changes in the autonomic nervous system manifest physiological abnormality. It has been reported that sleep and circadian rhythm differentially affect the activity of the sympathetic and parasympathetic nervous system (Burgess et al., 1997). Moreover, muscarinic type 2, 3, and 4 acetylcholine receptors in airway tissues (i.e., trachea, bronchus, and lung) of adult mice are expressed in a circadian manner via parasympathetic regulation (Bando et al., 2007). Thus, it is possible that autonomic innervation of airway tissues regulated by circadian rhythm or other behaviors (such as sleep and suckling) mitigate or manifest respiratory defect in the $\mathrm{KO}$ neonatal mice to determine their life or death. Such an idea remains to be further investigated.

\section{References}

Albacker LA, Chaudhary V, Chang YJ, Kim HY, Chuang YT, Pichavant M, DeKruyff RH, Savage PB, Umetsu DT (2013) Invariant natural killer T cells recognize a fungal glycosphingolipid that can induce airway hyperreactivity. Nat Med 19:1297-1304. CrossRef Medline

Arteaga-Solis E, Zee T, Emala CW, Vinson C, Wess J, Karsenty G (2013) Inhibition of leptin regulation of parasympathetic signaling as a cause of extreme body weight-associated asthma. Cell Metab 17:35-48. CrossRef Medline

Astin TW, Barer GR, Shaw JW, Warren PM (1973) The action of carbon dioxide on constricted airways. J Physiol 235:607-623. CrossRef Medline
Bando H, Nishio T, van der Horst GT, Masubuchi S, Hisa Y, Okamura H (2007) Vagal regulation of respiratory clocks in mice. J Neurosci 27: 4359-4365. CrossRef Medline

Bejjani C, Machaalani R, Waters KA (2013) The dorsal motor nucleus of the vagus (DMNV) in sudden infant death syndrome (SIDS): pathways leading to apoptosis. Respir Physiol Neurobiol 185:203-210. CrossRef Medline

Bennett JA, Kidd C, Latif AB, McWilliam PN (1981) A horseradish peroxidase study of vagal motoneurones with axons in cardiac and pulmonary branches of the cat and dog. Q J Exp Physiol 66:145-154. CrossRef Medline

Bianchi AL, Denavit-Saubié M, Champagnat J (1995) Central control of breathing in mammals: neuronal circuitry, membrane properties, and neurotransmitters. Physiol Rev 75:1-45. Medline

Blanchi B, Kelly LM, Viemari JC, Lafon I, Burnet H, Bévengut M, Tillmanns S, Daniel L, Graf T, Hilaire G, Sieweke MH (2003) MafB deficiency causes defective respiratory rhythmogenesis and fatal central apnea at birth. Nat Neurosci 6:1091-1100. CrossRef Medline

Browning KN, Travagli RA (2014) Central nervous system control of gastrointestinal motility and secretion and modulation of gastrointestinal functions. Compr Physiol 4:1339-1368. CrossRef Medline

Burgess HJ, Trinder J, Kim Y, Luke D (1997) Sleep and circadian influences on cardiac autonomic nervous system activity. Am J Physiol 273:H1761H1768. Medline

Burgold T, Voituron N, Caganova M, Tripathi PP, Menuet C, Tusi BK, Spreafico F, Bévengut M, Gestreau C, Buontempo S, Simeone A, Kruidenier L, Natoli G, Casola S, Hilaire G, Testa G (2012) The H3K27 demethylase JMJD3 is required for maintenance of the embryonic respiratory neuronal network, neonatal breathing, and survival. Cell Rep 2:1244-1258. CrossRef Medline

Caubit X, Thoby-Brisson M, Voituron N, Filippi P, Bévengut M, Faralli H, Zanella S, Fortin G, Hilaire G, Fasano L (2010) Teashirt 3 regulates development of neurons involved in both respiratory rhythm and airflow control. J Neurosci 30:9465-9476. CrossRef Medline

Chang YW, Huang YS (2014) Arsenite-activated JNK signaling enhances CPEB4-Vinexin interaction to facilitate stress granule assembly and cell survival. PloS One 9:e107961. CrossRef Medline

Chao HW, Tsai LY, Lu YL, Lin PY, Huang WH, Chou HJ, Lu WH, Lin HC, Lee PT, Huang YS (2013) Deletion of CPEB3 enhances hippocampusdependent memory via increasing expressions of PSD95 and NMDA receptors. J Neurosci 33:17008-17022. CrossRef Medline

Chen PJ, Huang YS (2012) CPEB2-eEF2 interaction impedes HIF-1alpha RNA translation. EMBO J 31:959-971. CrossRef Medline

Corbett EK, Batten TF, Kaye JC, Deuchars J, McWilliam PN (1999) Labelling of rat vagal preganglionic neurones by carbocyanine dye DiI applied to the heart. Neuroreport 10:1177-1181. CrossRef Medline

Crone SA, Viemari JC, Droho S, Mrejeru A, Ramirez JM, Sharma K (2012) Irregular breathing in mice following genetic ablation of V2a neurons. J Neurosci 32:7895-7906. CrossRef Medline

Dauger S, Guimiot F, Renolleau S, Levacher B, Boda B, Mas C, Nepote V, Simonneau M, Gaultier C, Gallego J (2001) MASH-1/RET pathway involvement in development of brain stem control of respiratory frequency in newborn mice. Physiol Genomics 7:149-157. CrossRef Medline

Duane SF, Weir EK, Stewart RM, Niewoehner DE (1979) Distal airway responses to changes in oxygen and carbon dioxide tensions. Respir Physiol 38:303-311. CrossRef Medline

Dubreuil V, Ramanantsoa N, Trochet D, Vaubourg V, Amiel J, Gallego J, Brunet JF, Goridis C (2008) A human mutation in Phox2b causes lack of $\mathrm{CO} 2$ chemosensitivity, fatal central apnea, and specific loss of parafacial neurons. Proc Natl Acad Sci U S A 105:1067-1072. CrossRef Medline

Dutschmann M, Herbert H (2006) The Kolliker-Fuse nucleus gates the postinspiratory phase of the respiratory cycle to control inspiratory offswitch and upper airway resistance in rat. Eur J Neurosci 24:1071-1084. CrossRef Medline

Feldman JL, Del Negro CA, Gray PA (2013) Understanding the rhythm of breathing: so near, yet so far. Annu Rev Physiol 75:423-452. CrossRef Medline

Fleming PJ, Blair PS, Pease A (2015) Sudden unexpected death in infancy: aetiology, pathophysiology, epidemiology and prevention in 2015. Arch Dis Child 100:984-988. CrossRef Medline

Fontán JJ, Diec CT, Velloff CR (2000) Bilateral distribution of vagal motor 
and sensory nerve fibers in the rat's lungs and airways. Am J Physiol Regul Integr Comp Physiol 279:R713-R728. Medline

Fortin G, Thoby-Brisson M (2009) Embryonic emergence of the respiratory rhythm generator. Respir Physiol Neurobiol 168:86-91. CrossRef Medline

Frank DU, Carter KL, Thomas KR, Burr RM, Bakker ML, Coetzee WA, Tristani-Firouzi M, Bamshad MJ, Christoffels VM, Moon AM (2012) Lethal arrhythmias in Tbx3-deficient mice reveal extreme dosage sensitivity of cardiac conduction system function and homeostasis. Proc Natl Acad Sci U S A 109:E154-E163. CrossRef Medline

Gautam M, Noakes PG, Moscoso L, Rupp F, Scheller RH, Merlie JP, Sanes JR (1996) Defective neuromuscular synaptogenesis in agrin-deficient mutant mice. Cell 85:525-535. CrossRef Medline

Guyenet PG, Mulkey DK (2010) Retrotrapezoid nucleus and parafacial respiratory group. Respir Physiol Neurobiol 173:244-255. CrossRef Medline

Hadziefendic S, Haxhiu MA (1999) CNS innervation of vagal preganglionic neurons controlling peripheral airways: a transneuronal labeling study using pseudorabies virus. J Auton Nerv Syst 76:135-145. CrossRef Medline

Haselton JR, Solomon IC, Motekaitis AM, Kaufman MP (1992) Bronchomotor vagal preganglionic cell bodies in the dog: an anatomic and functional study. J Appl Physiol 73:1122-1129. Medline

Hashimoto T, Kihara M, Ishida J, Imai N, Yoshida S, Toya Y, Fukamizu A, Kitamura H, Umemura S (2006) Apelin stimulates myosin light chain phosphorylation in vascular smooth muscle cells. Arterioscler Thromb Vasc Biol 26:1267-1272. CrossRef Medline

Haxhiu MA, Jansen AS, Cherniack NS, Loewy AD (1993) Cns innervation of airway-related parasympathetic preganglionic neurons-a transneuronal labeling study using pseudorabies virus. Brain Res 618:115-134. CrossRef Medline

Hilaire G (2006) Endogenous noradrenaline affects the maturation and function of the respiratory network: possible implication for SIDS. Auton Neurosci 126-127:320-331. Medline

Hilaire G, Monteau R, Errchidi S (1989) Possible modulation of the medullary respiratory rhythm generator by the noradrenergic $\mathrm{A} 5$ area: an in vitro study in the newborn rat. Brain Res 485:325-332. CrossRef Medline

Hirsch MR, Tiveron MC, Guillemot F, Brunet JF, Goridis C (1998) Control of noradrenergic differentiation and Phox2a expression by MASH1 in the central and peripheral nervous system. Development 125:599-608. Medline

Huang YS, Kan MC, Lin CL, Richter JD (2006) CPEB3 and CPEB4 in neurons: analysis of RNA-binding specificity and translational control of AMPA receptor GluR2 mRNA. EMBO J 25:4865-4876. CrossRef Medline

Huang ZG, Wang X, Dergacheva O, Mendelowitz D (2005) Prenatal nicotine exposure recruits an excitatory pathway to brainstem parasympathetic cardioinhibitory neurons during hypoxia/hypercapnia in the rat: implications for sudden infant death syndrome. Pediatr Res 58:562-567. CrossRef Medline

Hu W, Yuan B, Lodish HF (2014) Cpeb4-mediated translational regulatory circuitry controls terminal erythroid differentiation. Dev Cell 30:660672. CrossRef Medline

Jordan D (2001) Central nervous pathways and control of the airways. Respir Physiol 125:67-81. CrossRef Medline

Kahn A, Riazi J, Blum D (1983) Oculocardiac reflex in near miss for sudden infant death syndrome infants. Pediatrics 71:49-52. Medline

Kalia M, Mesulam MM (1980) Brain stem projections of sensory and motor components of the vagus complex in the cat: II. Laryngeal, tracheobronchial, pulmonary, cardiac, and gastrointestinal branches. J Comp Neurol 193:467-508. CrossRef Medline

Kato I, Franco P, Groswasser J, Kelmanson I, Togari H, Kahn A (2000) Frequency of obstructive and mixed sleep apneas in 1,023 infants. Sleep 23:487-492. Medline

Kudo M, Khalifeh Soltani SM, Sakuma SA, McKleroy W, Lee TH, Woodruff PG, Lee JW, Huang K, Chen C, Arjomandi M, Huang X, Atabai K (2013) Mfge8 suppresses airway hyperresponsiveness in asthma by regulating smooth muscle contraction. Proc Natl Acad Sci U S A 110:660-665. CrossRef Medline

Langsdorf A, Radzikinas K, Kroten A, Jain S, Ai X (2011) Neural crest cell origin and signals for intrinsic neurogenesis in the mammalian respiratory tract. Am J Respir Cell Mol Biol 44:293-301. CrossRef Medline

Leiria LO, Arantes-Costa FM, Calixto MC, Alexandre EC, Moura RF, Folli F, Prado CM, Prado MA, Prado VF, Velloso LA, Donato J Jr, Antunes E, Martins MA, Saad MJ (2015) Increased airway reactivity and hyperinsulinemia in obese mice are linked by ERK signaling in brain stem cholinergic neurons. Cell Rep 11:934-943. CrossRef Medline

Llewellyn-Smith IJ, Verberne AJM (2011) Central regulation of autonomic functions, 2nd edition. New York: Oxford UP.

Machaalani R, Waters KA (2008) Neuronal cell death in the sudden infant death syndrome brainstem and associations with risk factors. Brain 131: 218-228. Medline

Machaalani R, Waters KA (2014) Neurochemical abnormalities in the brainstem of the sudden infant death syndrome (SIDS). Paediatr Respir Rev 15:293-300. CrossRef Medline

Mallard C, Tolcos M, Leditschke J, Campbell P, Rees S (1999) Reduction in choline acetyltransferase immunoreactivity but not muscarinic-m2 receptor immunoreactivity in the brainstem of SIDS infants. J Neuropathol Exp Neurol 58:255-264. CrossRef Medline

Marchenko V, Sapru HN (2000) Different patterns of respiratory and cardiovascular responses elicited by chemical stimulation of dorsal medulla in the rat. Brain Res 857:99-109. CrossRef Medline

McGovern AE, Mazzone SB (2010) Characterization of the vagal motor neurons projecting to the Guinea pig airways and esophagus. Front Neurol 1:153. CrossRef Medline

Mitchell EA, Krous HF (2015) Sudden unexpected death in infancy: a historical perspective. J Paediatr Child Health 51:108-112. CrossRef Medline

Mitchell EA, Ford RP, Stewart AW, Taylor BJ, Becroft DM, Thompson JM, Scragg R, Hassall IB, Barry DM, Allen EM (1993) Smoking and the sudden infant death syndrome. Pediatrics 91:893-896. Medline

Neff RA, Wang J, Baxi S, Evans C, Mendelowitz D (2003) Respiratory sinus arrhythmia: endogenous activation of nicotinic receptors mediates respiratory modulation of brainstem cardioinhibitory parasympathetic neurons. Circ Res 93:565-572. CrossRef Medline

Nsegbe E, Wallén-MackenzieA, Dauger S, Roux JC, Shvarev Y, Lagercrantz H, Perlmann T, Herlenius E (2004) Congenital hypoventilation and impaired hypoxic response in Nurr1 mutant mice. J Physiol 556:43-59. CrossRef Medline

Onimaru H, Ikeda K, Kawakami K (2009) Phox2b, RTN/pFRG neurons and respiratory rhythmogenesis. Respir Physiol Neurobiol 168:13-18. CrossRef Medline

Paton JF (1996) The ventral medullary respiratory network of the mature mouse studied in a working heart-brainstem preparation. J Physiol 493: 819-831. CrossRef Medline

Persson K, Rekling JC (2011) Population calcium imaging of spontaneous respiratory and novel motor activity in the facial nucleus and ventral brainstem in newborn mice. J Physiol 589:2543-2558. CrossRef Medline

Qian Y, Fritzsch B, Shirasawa S, Chen CL, Choi Y, Ma Q (2001) Formation of brainstem (nor)adrenergic centers and first-order relay visceral sensory neurons is dependent on homeodomain protein Rnx/Tlx3. Genes Dev 15:2533-2545. CrossRef Medline

Schechtman VL, Lee MY, Wilson AJ, Harper RM (1996) Dynamics of respiratory patterning in normal infants and infants who subsequently died of the sudden infant death syndrome. Pediatr Res 40:571-577. CrossRef Medline

Schoenberg DR, Maquat LE (2012) Regulation of cytoplasmic mRNA decay. Nat Rev Genet 13:246-259. CrossRef Medline

Shirasawa S, Arata A, Onimaru H, Roth KA, Brown GA, Horning S, Arata S, Okumura K, Sasazuki T, Korsmeyer SJ (2000) Rnx deficiency results in congenital central hypoventilation. Nat Genet 24:287-290. CrossRef Medline

Smith JC, Ellenberger HH, Ballanyi K, Richter DW, Feldman JL (1991) Pre-Botzinger complex: a brainstem region that may generate respiratory rhythm in mammals. Science 254:726-729. CrossRef Medline

Spengler CM, Gozal D, Shea SA (2001) Chemoreceptive mechanisms elucidated by studies of congenital central hypoventilation syndrome. Respir Physiol 129:247-255. CrossRef Medline

Strohl KP (1985) Respiratory activation of the facial nerve and alar 
muscles in anaesthetized dogs. J Physiol 363:351-362. CrossRef Medline

Takanaga A, Hayakawa T, Tanaka K, Kawabata K, Maeda S, Seki M (2003) Immunohistochemical characterization of cardiac vagal preganglionic neurons in the rat. Auton Neurosci 106:132-137. CrossRef Medline

Tolcos M, McGregor H, Walker D, Rees S (2000) Chronic prenatal exposure to carbon monoxide results in a reduction in tyrosine hydroxylaseimmunoreactivity and an increase in choline acetyltransferaseimmunoreactivity in the fetal medulla: implications for sudden infant death syndrome. J Neuropathol Exp Neurol 59:218-228. CrossRef Medline

Tsai LY, Chang YW, Lin PY, Chou HJ, Liu TJ, Lee PT, Huang WH, Tsou YL, Huang YS (2013) CPEB4 knockout mice exhibit normal hippocampus- related synaptic plasticity and memory. PLoS One 8:e84978. CrossRef Medline

Twort CH, Cameron IR (1986) Effects of PCO2, pH and extracellular calcium on contraction of airway smooth muscle from rats. Respir Physiol 66:259-267. CrossRef Medline

Zhang WC, Peng YJ, Zhang GS, He WQ, Qiao YN, Dong YY, Gao YQ, Chen C, Zhang CH, Li W, Shen HH, Ning W, Kamm KE, Stull JT, Gao X, Zhu MS (2010) Myosin light chain kinase is necessary for tonic airway smooth muscle contraction. J Biol Chem 285:5522-5531. CrossRef Medline

Zhang XY, Ai HB, Cui XY (2006) Effects of nucleus ambiguus and dorsal motor nuclei of vagus on gastric $\mathrm{H}(+)$ and $\mathrm{HCO}(3)(-)$ secretion in rats. World J Gastroenterol 12:3271-3274. CrossRef Medline 